Research Article

\title{
Decisions of E-Commerce Supply Chain under Consumer Returns and Different Power Structures
}

\author{
Liang Shen, ${ }^{1}$ Runjie Fan, ${ }^{1}$ and Yuyan Wang $\mathbb{D}^{2}$ \\ ${ }^{1}$ School of Public Finance and Taxation, Shandong University of Finance and Economics, Jinan, Shandong 250014, China \\ ${ }^{2}$ School of Management Science and Engineering, Shandong University of Finance and Economics, Jinan, \\ Shandong 250014, China \\ Correspondence should be addressed to Yuyan Wang; wangyuyan1224@126.com
}

Received 22 September 2020; Revised 8 October 2020; Accepted 24 October 2020; Published 16 November 2020

Academic Editor: Ming Bao Cheng

Copyright (C) 2020 Liang Shen et al. This is an open access article distributed under the Creative Commons Attribution License, which permits unrestricted use, distribution, and reproduction in any medium, provided the original work is properly cited.

Considering the growing phenomenon of consumer returns and channel power struggles in e-commerce supply chains (ESCs), the ESC model is constructed and its equilibrium solutions are calculated and compared. Further, the consumer utility function is constructed to explore the impact of returns and dominant enterprises on consumer utility. Based on this, the "return cost-sharing and commission readjusting" contract is designed to maximize both ESC and consumer utility. Finally, the paper validates and further analyzes conclusions through numerical simulation. The main conclusions are as follows: higher return rates and return handling costs will reduce market demand and ESC profits, while higher salvage value of returned products will have a positive impact on ESC, but the above factors will not affect the online service level under decentralized decisions. The impact of consumer's service quality preferences on manufacturer's profits and e-commerce platform's profit is determined by channel power structure. The impact of return rate on consumer utility depends on two factors: the decision-making model and the hidden cost of consumer returns.

\section{Introduction}

With the high growth of the network economy, more and more products are sold through online channels, which has led to the formation of the e-commerce supply chain (ESC). In recent years, the e-commerce platform (as e-platform) has emerged as a reliable information center and trading platform in ESC. Through the e-platform, products are sold directly by manufacturers to consumers, which broadens the direct sales model in ESC. This direct sales model brings multiple benefits to manufacturers. On the one hand, due to the low entry barriers and price advantages of e-platforms, manufacturers' operational costs can be reduced and their scale is no longer limited by space $[1,2]$. On the other hand, e-platforms enable manufacturers to reach a larger number of customer segments [3] and make them obtain consumer feedback and adjust their corporate strategies timely $[4,5]$, which ultimately brings increased economic benefits to manufacturers. For consumers, the rapid development of
ESC increases their shopping flexibility [6], expands their shopping options [7], and reduces their travel time and cost [8]. As a result, more and more manufacturers are entering e-platforms and more and more consumers are buying online. FTI consulting forecasts e-commerce sales to exceed $\$ 1$ trillion in 2027 [9], which means that ESC has not only economic and operational advantages but also broad growth prospects.

However, the development of ESC has exacerbated consumer returns. Customer returns have always been a serious problem for traditional supply chains $[10,11]$, while online sales have higher return rates than offline store sales [12-14]. Invesp infographics statistics show that the return rate for brick-and-mortar stores is $8.89 \%$, while online order products have a return rate of more than $30 \%$ [15]. More seriously, return rates will be higher in the aftermath of major promotions, such as "Black Friday" in US and "Double Eleven" in China [16]. The above phenomenon is partly because online shoppers cannot access products, 
which increases the inaccuracy of their predictions for product value. Alternatively, the e-commerce sales environment is very complex, where false information and fake reviews can induce consumers to make incorrect choices. Additionally, the return regulations for commodities have become the primary consideration when consumers shopping online [17-19]. As a result, most e-platforms and manufacturers deliver return services. The delivery of return services can enable manufacturers, especially fashion manufacturers, to keep abreast of customer feedback and form a competitive advantage [20, 21], alleviating consumers' concerns about valuation uncertainty [22], and increase consumer willingness to buy instantly $[23,24]$ and the likelihood of repeat purchases on the platform in the future $[25,26]$. However, serious consumer returns will inevitably result in loss of profits for manufacturers, influencing pricing and other decisions of ESC participants, and bring greater risks for the management of ESC operations. Therefore, incorporating consumer returns into ESC's decision-making and exploring its impact on ESC members and systems is a very realistic study that needs to be developed.

In addition, manufacturers introducing online direct sales channels will face competition from e-platforms for channel power. Unlike dual-channel supply chains where manufacturers set up online sales channels, in ESC, both manufacturers and e-platforms have channel power [27]. Nowadays, the power of e-platforms is growing, and the phenomenon of the transfer of the dominant power from manufacturers to e-platforms has emerged in ESC. For well-known manufacturers (e.g., Apple, P\&G, and Galanz), they still manage to maintain their ESC dominance. However, for some small- and medium-sized manufacturers, they are already at a disadvantage in cooperating with some powerful e-platforms (e.g., Amazon, JD, and Taobao) because such platforms have formed a large user base and have well-developed entry rules. Different channel power structures will certainly have an impact on ESCs' decisions and profits and further influence consumer return behavior and purchase utility. Which channel power structure is more conducive to the stable operation of the ESC? How do ESC participants in different channel power structures make decisions to maximize their profits? Do consumer returns affect ESC or consumer utility differently under different channel power structures? The existing research does not provide clear answers to these questions. Therefore, this paper explores the optimal solution to ESC under different channel power structures and draws conclusions on the impact of channel power structure on ESC efficiency and consumer utility.

In the ESC, the increase in returns and the instability of dominant enterprise have become issues that every ESC member has to face when they make decisions. To clarify these issues, the article researches the following aspects:

(1) Considering consumer returns and channel power, what are the optimal decisions for each ESC member? What is the impact of returns on ESC?
(2) How does the channel power structure of ESC affect the decisions of ESC members? Under different channel powers, do the returns-related variables and consumer preferences affect ESC differently? Which channel power structure is most profitable for members and ESC?

(3) Many consumers are addicted to returning goods, is the behavior of returning goods beneficial to consumers themselves? How do return rates and consumer's service quality preferences affect consumer utility? What are the differences in consumer utility under different channel powers?

(4) How can return handling costs and commissions be incorporated into the ESC coordination process? How to design a new contract to maximize ESC efficiency and consumer utility?

Based on the serious consumer returns of ESCs and considering the different channel power structures, the paper examines the impact of channel structures and consumer returns on ESC. Moreover, the paper establishes an extended model of consumer utility, studies the impact of return rates and consumer's service quality preferences on consumer utility, and seeks a balance between system performance and consumer utility. Finally, the return handling costs and commissions are considered, and new coordination mechanisms are designed to optimize ESC profits and maximize consumer utility. The main contributions are listed as follows:

(1) The paper considers the independent e-platform as an ESC decision-maker and examines the influence of return-related variables on the e-platform's service level. Meanwhile, the influence of consumers' service quality preference on ESC and market demand is addressed. The study finds that, regardless of the channel power structure, the return rate does not affect the e-platform's service level (different from [28]). Increasing consumer service preferences will promote sales prices and service level (unlike [29]) and increase market demand and ESC profitability (unlike [30]). Differently, the effect of consumer service preferences on the profitability of manufacturer and e-platform depends on the channel power of ESC. Additionally, the paper on salvage value and return handling cost of returned products is not limited to the choice of return strategy and pricing (unlike [11, 31, 32]). The impact of salvage value and return handling costs on the e-platform's service level, market demand and return volume, ESC members, and system profits is also discussed.

(2) In the context of consumer returns, the paper explores the impact of channel structures on ESC. Some conclusions are similar to the studies of Wang et al. [33] and Han and Wang [34], but several previously unavailable findings are found. First, the dominant manufacturer brings higher product market demand, which is facilitated by higher service level at this time. At the same time, the dominant 
manufacturer also leads to a benign increase in consumer returns. Moreover, increased consumer's service quality preferences, regardless of the power structure, lead to higher profits for the manufacturer, but e-platform cannot always profit from consumer service preferences. When manufacturer dominates ESC, although the e-platform increased service investment due to the increase in consumer's service quality preferences, it could not profit from it.

(3) In the paper, an extension model of consumer utility is constructed, and the effects of return rates, channel power structures, and consumer service preferences on consumer utility are explored. The conclusions differ from the existing literature, such as Yan et al., [35]; Zhang et al. [36]; Yan et al. [35]; and Ma et al., [16]. The paper found that return behavior does not always improve consumer utility. The impact of the return rate on consumer utility depends on two factors: the decision-making mode and the consumer's hidden cost of returns. Moreover, the study compares consumer utility under different power structures and finds that centralized decisions can maximize consumer utility. The influence of channel power and consumer service preference on consumer utility depends on consumer price preference and return rate.

(4) Unlike the coordination mechanisms studied in previous literature, for ESCs with consumer returns, the study uses both commissions and return handling costs as adjustment tools to design a new "return cost-sharing and commission readjusting" contract. The contract maximizes ESC efficiency and consumer utility, which offers a new approach to the design of the ESC coordination mechanism.

The remainder of the study is designed below. The relevant literature is reviewed in Section 2. ESC model is described in Section 3. Section 4 presents and analyzes equilibrium solutions under different models. Section 5 constructs an extension model of consumer utility. Section 6 designs the "return cost-sharing and commission readjusting" contract to maximize system efficiency and consumer utility. Numerical analysis is given in Section 7 from different perspectives. Finally, Section 8 summarizes the paper and depicts management insights.

\section{Literature Review}

The paper aims to examine how ESC members under different power structures make decisions and coordinate when there is significant consumer return behavior in the e-commerce market. The study allows for a literature review of the three streams of consumer returns, channel power structure, and coordination mechanisms.

The first stream is consumer returns in supply chains. Currently, most of the relevant literature focuses on the study of consumer returns in traditional supply chains [37-39]. There are some scholars who have included manufacturers' or retailers' online sales channels in their exploration of consumer returns. For example, Li et al. [40] discussed how consumer returns affect return policies, product quality, and pricing of the online direct sales manufacturer. Based on retailers' online sales channels and consumer returns, Balakrishnan et al. [41] examined the effects of consumers' transition from offline to online browsing on online pricing and profits. Considering the return policy, Batarfi et al. [42] demonstrated that a dualchannel strategy is more beneficial to chains. Ji et al. [43] paid attention to consumers' choice of return channels and investigated the return strategies in the dual-channel supply chain. Taleizadeh et al. [44] showed that consumer return decisions depend on the refund amount and product quality. Targeting cross-channel returns in dual-channel supply chains, Radhi and Zhang [45] and Radhi and Zhang [3] studied how the return phenomenon affects product pricing and sourcing, while $\mathrm{He}$ et al. [46] obtained ordering and pricing strategies for new and renovated products. Further, the issue of consumer returns has been incorporated into the research of ESCs where e-platforms are covered. For example, Ma et al. [16] found the extent to which return policies affect pricing and profits in relation to retailers' unit purchase costs and market return rates. Cao et al. [32] accounted for the channel choice of whether retailers should enter e-platforms and found that the choice mainly depends on the e-platform's annual service fee. From the above literature, few scholars have considered consumer returns in ESC. Although some scholars consider online sales channels, most of these channels are controlled by manufacturers or retailers and no e-platform is included. Among them, Ma et al. [16] defined an independent e-platform, but they are targeted at the choice of return policies, which differs significantly from the research direction of this study.

The second stream is the channel power structure in supply chains. Currently, channel structure's impact on channel management $[47,48]$, pricing $[8,49]$, and system performance $[50,51]$ has been fully explored in supply chains. The study highlights a review of the literature on power structures in ESCs. In ESC's channel power study, most of the literature considers manufacturers' online sales channels. For example, Taleizadeh et al. [30] developed a two-echelon ESC composed of two manufacturers and retailers, where both manufacturers have online sales channels. This study showed that the channel power structure determines the maximum profit of ESC. Similarly, Zhao et al. [52] examined how channel power affects system profits, but they assumed that only one manufacturer had the online sales channel. This study found that leading manufacturers opening the online sales channel will lose their own profits. Focusing on the power struggle between manufacturers and retailers, Ke et al. [53] and Chun and Park [54] examined how channel structures affect pricing strategies and manufacturers' marketing strategies, respectively. There are a few pieces of literature that consider retailers' online sales channels. For example, Chen et al. [55] constructed an $\mathrm{O}_{2} \mathrm{O}$ hybrid dual-channel model and investigated how channel power affects pricing and financial performance. Basak et al. [56] explored how showrooming affects traditional and online retailers under different power 
structures. However, in previous literature, they do not regard the independent e-platform as a decision-making subject, much less consider the channel power struggle between e-platforms and manufacturers. More relevant to this study, Wang et al. [27] and Liu and Ke [57] researched the impact of power structures between manufacturers and e-platforms on product pricing, but neither of them considered the serious consumer returns in ESC.

The third stream is the coordination mechanism in supply chains. For supply chains with consumer returns, Xu et al. [58] considered different return periods and proposed differentiated repurchase contracts to achieve supply chain coordination. Heydari and Ghasemi [59] designed revenuesharing contracts and realized risk sharing and profit growth for reverse supply chain members based on the uncertainty of return product quality. Wang et al. [38] explored how suppliers can coordinate supply chains with returns through options pricing. Further, addressing the more complex issue of returns in the online channel, Yan and Pei [60] constructed an $\mathrm{O}_{2} \mathrm{O}$ competition model and developed revenuesharing contracts to resolve the conflict of returns policies in dual-channel supply chain. Focusing on loss-averse consumer returns, $\mathrm{Gu}$ et al. [61] used revenue and cost-sharing contracts to achieve dual-channel fresh agricultural product ESC coordination and captured Pareto improvement areas for suppliers and e-tailers under coordinated conditions. Recognizing the infringement of suppliers' online sales channels on retailers' offline sales, Li and Jiang [22] studied the return strategy and realized a dual-channel supply chain coordination through the two-part tariff contract. The above literature provides the basis for this paper, but they cannot achieve ESC coordination with independent e-platforms.

For supply chains with online channels, Liu et al. [62] mitigated courier capacity overload through option covenants in the supply chain of online retailers. Song and He [63] studied the coordination mechanism of fresh ESC and showed that the cost-sharing contract for preservation efforts will lead to lower demand, but the cost-sharing revenue-sharing contract can effectively coordinate ESC. Amrouche et al. [64] considered online retailers and analyzed the effectiveness of different cooperation mechanisms (minimum pricing strategy, omnichannel price, and revenue-sharing cooperation) in different ESC environments. However, this literature does not integrate e-platforms into coordinated studies of ESC. Incorporating e-platforms into the decision-making process of ESC, Dong et al. [65] found that the revenue-sharing pacts can coordinate ESC in demand determination situations, but transfer payments are required. Zhang et al. [66] found that revenue-sharing pacts allow the leader-follower structure in e-commerce logistics systems to be coordinated. Similarly, Zhong et al. [67] demonstrated that revenue-sharing pacts allow optimizing the profitability of three-echelon logistics service supply chains. In contrast to the coordination mechanisms mentioned above, carbon cost sharing is used to achieve lowcarbon ESC coordination in Han and Wang [34]. These papers provide a great deal of research for ESC coordination but do not address the unique profitability mode of e-platforms, that is, charging commissions, which is the core of the coordination mechanism in this paper. The research of Wang et al. [33] and Wang et al. [68] needs to be highlighted. They used commissions as an adjustment tool, established cost-sharing joint commission contracts, and coordinated ESCs with fairness concerns and altruistic concerns. However, they did not study the flood of consumer returns in the ESC.

It can be seen from the above literature that the previous research only considers one or more of the below factors, such as online sales channels, channel power, customer returns, service level, and coordination contract. The paper synthesizes the above factors and examines the effect of consumer returns on ESC and consumer utility under different channel powers. Additionally, product pricing and e-platform service inputs under different power structures are decided, and an ESC coordination contract is designed in the return environment. The specific differences between this paper and other studies are summarized in Table 1.

\section{Model Description}

In this study, an ESC consisting of a manufacturer (called he) and an e-platform (called she) is proposed. In the Taobao (http://www.taobao.com) platform's basic operating mode, consumers' purchase and return information is conveyed and confirmed through the platform, but the actual delivery and return logistics do not go through the platform. Thus, the model is constructed as follows. In ESC, the manufacturer releases the product information through e-platform, from which products can be directly sold to consumers. For consumers, when they want to perform a return, they can apply for a return through e-platform and return products directly to the manufacturer. After that, the manufacturer who received the returned product will refund the full payment to the consumer. Such a sales and return model is used extensively in JD (not self-managed), Amazon (FBM), and Pinduoduo. At the same time, the operational model is in line with the operational framework of existing research $[32,69,70]$. The model structure is shown in Figure 1.

When a manufacturer enters an independent e-platform, it not only defrays fixed fees such as fixed technical fees and deposits but also pays commissions based on sales volume. Moreover, commissions will vary depending on the brand and type of product. Of course, the services provided by the e-platform for manufacturers will also be different depending on the commission. These services mainly include the quantity and time of advertising for products, the quality of service for quick returns and exchanges, booths in online stores, sales agency operation, storage services, logistics services, payment services, after-sales service, and credit maintenance. It can be seen from the above information that the research for commissions is more meaningful than that for the fixed fee paid by the manufacturer. Therefore, models are simplified in this paper to better analyze e-platform's service level. That is, fixed costs are ignored, while the unit commission is used as a parameter. The notations and assumptions used in the paper are shown in Table 2. 
TABLE 1: Papers that are most related to our research.

\begin{tabular}{|c|c|c|c|c|c|}
\hline Author & Online sales channels & Channel power & Customer returns & Service level & Coordination contract \\
\hline Yan and Pei [60] & $\sqrt{ }$ & & $\sqrt{ }$ & & $\sqrt{ }$ \\
\hline $\mathrm{Gu}$ et al. [61] & $\sqrt{ }$ & & $\sqrt{ }$ & & $\sqrt{ }$ \\
\hline $\mathrm{Xu}$ et al. [37] & & & $\sqrt{ }$ & & $\sqrt{ }$ \\
\hline Radhi and Zhang [45] & $\sqrt{ }$ & $\sqrt{ }$ & $\sqrt{ }$ & & \\
\hline Radhi and Zhang [3] & $\sqrt{ }$ & & $\sqrt{ }$ & & \\
\hline He et al. [46] & $\sqrt{ }$ & & $\sqrt{ }$ & & \\
\hline Wang et al. [38] & & & $\sqrt{ }$ & & $\sqrt{ }$ \\
\hline Zhang et al. [8] & $\sqrt{ }$ & & $\sqrt{ }$ & & $\sqrt{ }$ \\
\hline Ma et al. [16] & $\sqrt{ }($ e-platform is included $)$ & & $\sqrt{ }$ & & \\
\hline $\mathrm{Li}$ and Jiang [22] & $\sqrt{ }$ & & $\sqrt{ }$ & & $\sqrt{ }$ \\
\hline Taleizadeh et al. [30] & $\sqrt{ }$ & $\sqrt{ }$ & & & \\
\hline Zhao et al. [52] & $\sqrt{ }$ & $\sqrt{ }$ & & & \\
\hline Ke et al. [53] & $\sqrt{ }$ & $\sqrt{ }$ & & & \\
\hline Wang et al. [27] & $\sqrt{ }(\mathrm{e}$-platform is included $)$ & $\sqrt{ }$ & & $\sqrt{ }$ & \\
\hline Chun and Park [54] & $\sqrt{ }$ & $\sqrt{ }$ & & & \\
\hline Liu and Ke [57] & $\sqrt{ }$ (e-platform is included) & $\sqrt{ }$ & & & \\
\hline Wang et al. [33] & $\sqrt{ }($ e-platform is included $)$ & & & $\sqrt{ }$ & $\sqrt{ }$ \\
\hline Han and Wang [34] & $\sqrt{ }(\mathrm{e}$-platform is included $)$ & & & $\sqrt{ }$ & $\sqrt{ }$ \\
\hline Wang et al. [68] & $\sqrt{ }(\mathrm{e}$-platform is included $)$ & & & $\sqrt{ }$ & $\sqrt{ }$ \\
\hline This paper & $\sqrt{ }$ (e-platform is included $)$ & $\sqrt{ }$ & $\sqrt{ }$ & $\sqrt{ }$ & $\sqrt{ }$ \\
\hline
\end{tabular}

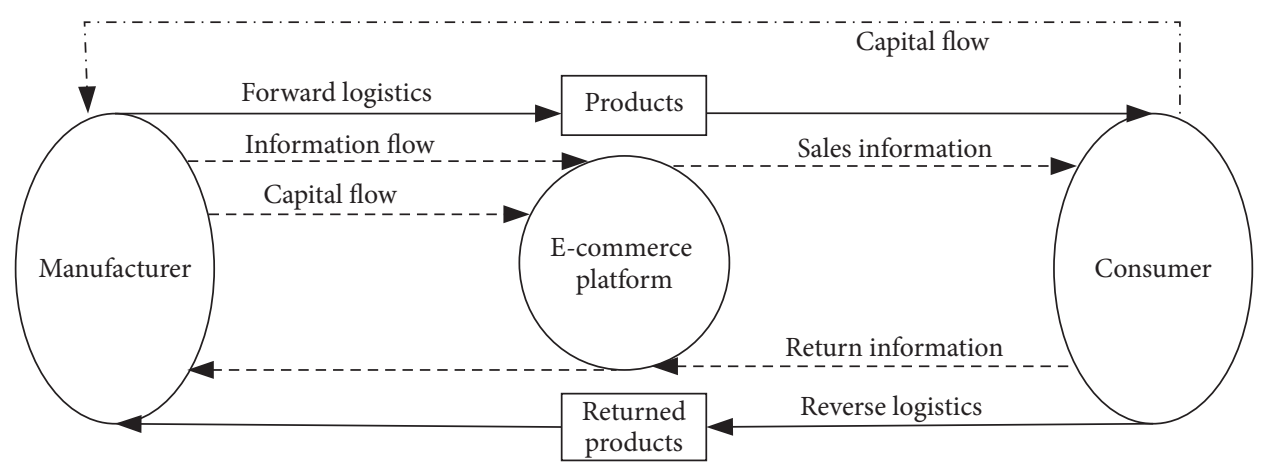

FIgUre 1: The model structure of ESC.

\section{Model Formulation and Equilibrium Solutions}

4.1. A Benchmark: Centralized Model. In this section, centralized decision-making is presented as a benchmark. Under this model, manufacturer and e-platform make decisions to maximize ESC profits. ESC's decision function is

$$
\max _{p, s} \pi=p D+(w-h) \varepsilon Q-c Q-k s^{2} .
$$

According to equation (1), Hessian matrix of $\pi(p, s)$ is derived as $H=\left[\begin{array}{cc}\partial^{2} \pi / \partial^{2} p & \partial^{2} \pi / \partial p \partial s \\ \partial^{2} \pi / \partial s \partial p & \partial^{2} \pi / \partial^{2} s\end{array}\right]=\left[\begin{array}{cc}-2 \beta & \gamma \\ \gamma & -k\end{array}\right]$. Since $2 k \beta-\gamma^{2}>0$, the optimal solution of $\pi(p, s)$ exists. The equilibrium solutions can be obtained by $\partial \pi / \partial p=0$ and $\partial \pi / \partial s=0$, as shown in Table 3 .

4.2. Decentralized Models. Due to the accelerated development of network economy and communication technology, channel power of e-platforms is growing. In recent years, a transfer in ESC dominance from manufacturers to e-platforms has been observed. Currently, there are two different channel power structures in the ESC: ESC with dominant manufacturer and ESC with dominant e-platform. These channel power structures are modeled and analyzed as follows:

Manufacturer's profit:

$$
\pi_{m}=(p-\rho) D+(w-h) \varepsilon Q-c Q .
$$

E-platform's profit:

$$
\pi_{e}=\rho D-k s^{2} .
$$

System profit of ESC:

$$
\pi=p D+(w-h) \varepsilon Q-c Q-k s^{2} .
$$

4.2.1. Decentralized Model with Dominant Manufacturer. If the manufacturer is more powerful, he will dominate ESC and become the leader (first mover in decision- 
TABle 2: Notations description.

\begin{tabular}{|c|c|}
\hline Notations & Description \\
\hline$p$ & The sales price of products (decision variable for manufacturer). \\
\hline$c$ & The unit production cost of products. \\
\hline$\rho$ & The unit commission paid by manufacturer. \\
\hline$\varepsilon$ & The consumer return rate. According to Ma et al. [16], $0<\varepsilon<1$ \\
\hline$h$ & $\begin{array}{l}\text { The return handling cost of the manufacturer. Referring to Xia et al. [71], assuming } h<w \text {, it means that it is profitable for the } \\
\text { manufacturer to process customer returns. }\end{array}$ \\
\hline$w$ & $\begin{array}{l}\text { The average salvage value of the returned products, which can be obtained through remanufacturing or secondary market sales. } \\
\text { Based on Chen and Chen }[11], w<c .\end{array}$ \\
\hline$s$ & $\begin{array}{l}\text { The service level of e-platform (decision variable for e-platform). According to Shen et al. [72] and Li et al. [73], the service } \\
\text { investment cost can be described as } C(s)=k s^{2} \text {, where } k(k>0) \text { is the elasticity coefficient of service investment cost. }\end{array}$ \\
\hline$D$ & $\begin{array}{l}\text { The market demand for products. Similar to Xie et al. [74] and Li et al. [75], this study assumes that the demand function is } \\
D=\alpha-\beta p+\gamma s \text {, in which } \alpha(\alpha>0) \text { represents the maximum demand in the potential market and } \beta(\beta>0) \text { and } \gamma(\gamma>0) \text { indicate } \\
\text { consumers' price preferences and consumers' service quality preferences, respectively. Moreover, } \alpha(1-\varepsilon)>\beta>\gamma>0 \text {, which } \\
\text { means that it is profitable for manufacturers to enter the market and consumers' preference for sales price over their preference } \\
\text { for service level. }\end{array}$ \\
\hline Q & $\begin{array}{c}\text { The actual sales of products. According to Radhi and Zhang [45] and Reimann [76], the study presumes that the actual sales } \\
\text { volume of product is } Q=D /(1-\varepsilon) .\end{array}$ \\
\hline$R$ & Volume of returns by consumers, and $R=Q-D=(\varepsilon D / 1-\varepsilon)$ \\
\hline$e, m$ & $e$ represents the e-platform and $m$ represents the manufacturer. \\
\hline$c^{*}, m^{*}, e^{*}$ & $\begin{array}{c}c^{*} \text { stands for centralized decision-making, } m^{*} \text { stands for decentralized decision-making led by manufacturer, and } e * \text { stands for } \\
\text { decentralized decision-making led by e-platform. }\end{array}$ \\
\hline$\pi_{i}^{n}$ & Profit of decision-maker $i$ under $n, i=e, m, n=c^{*}, m^{*}, e^{*}$ \\
\hline$\pi^{n}$ & Total profit of ESC system under $n, n=c^{*}, m^{*}, e^{*}$ \\
\hline
\end{tabular}

(1) Based on Chang and Yeh [77] and Scheriau, [78], the return handling cost is covered by manufacturer, and manufacturer implements a full refund policy for consumers.

Remarks

(2) During the actual operation of ESC, return orders are generally not counted as manufacturer sales. Therefore, the e-platform calculates sales based on completed and nonreturned orders.

(3) According to Wang et al. [79], the commission is set up earlier than the ESC decision. The commission appears as an exogenous variable in the paper.

(4) To make the study meaningful, assume $2 k \beta-\gamma^{2}>0$.

making) in working with smaller e-platforms. In this situation, both manufacturer and e-platform, as an independent economy, make decisions to maximize their own benefits. Based on this, manufacturer-led Stackelberg is formed; that is, manufacturer first determines $p$ according to the market demand. e-platform then decides $s$.

Equilibrium solutions can be solved by the backward induction method. Due to $\partial^{2} \pi_{e} / \partial s^{2}=-2 k<0, \pi_{e}$ is a concave function of $s$. By $\partial \pi_{e} / \partial s=0, s^{m *}$ can be obtained. Substituting $s^{m *}$ into $\pi_{m}$, since $\partial^{2} \pi_{m} / \partial p^{2}=-2 \beta<0, \pi_{m}$ is a concave function of $p$. Solving $\partial \pi_{m} / \partial p=0, p^{m *}$ can be solved. Then, the equilibrium solutions of the model can be obtained, as shown in Table 3.

\subsubsection{Decentralized Model with Dominant E-Platform.} When large third-party e-platforms (Tmall, JD, Amazon, etc.) form ESCs with small- or medium-sized manufacturers, e-platforms generally dominate ESCs. In the decisionmaking process, e-platform takes the lead in deciding $s$, followed by manufacturer in deciding $p$. Based on backward induction method (the solution is the same as 4.2 .1 ), the optimal decisions can be obtained in Table 3.

4.3. Comparative Analysis. In this section, the comparative analysis of models is presented for two purposes. On the one hand, the impact of changes in return-related parameters on ESC decisions and profits can be obtained. On the other hand, the impact of the channel power structure on ESC and the volume of returns can also be explored. Comparing and analyzing equilibrium solutions, Conclusions $1-5$ can be obtained.

\section{Conclusion 1}

(1) $p^{c *}, p^{m *}$, and $p^{e *}$ are positively related to $\varepsilon ; D^{c *}$, $D^{m *}$, and $D^{e *}$ are negatively related to $\varepsilon ; R^{c *}, R^{m *}$, and $R^{e *}$ are positively related to $\varepsilon ; \pi_{m}^{m *}, \pi_{e}^{m *}, \pi_{m}^{e *}$, $\pi_{e}^{e *}, \pi^{c *}, \pi^{m *}$, and $\pi^{e *}$ are negatively related to $\varepsilon$.

(2) $s^{c *}$ is negatively related to $\varepsilon$, but $s^{m *}$ and $s^{e^{*}}$ are independent of $\varepsilon$.

See Appendix A for proof.

According to Conclusion 1, one has the following:

(1) In ESC, higher product return rates result in higher sales prices, lower market demand, and higher volume of returns, which ultimately results in lower profits for manufacturer, e-platform, and ESC system. This is because the increase in the return rate causes higher return handling fees for the manufacturer, which results in higher total operating costs for him. To compensate for lost 


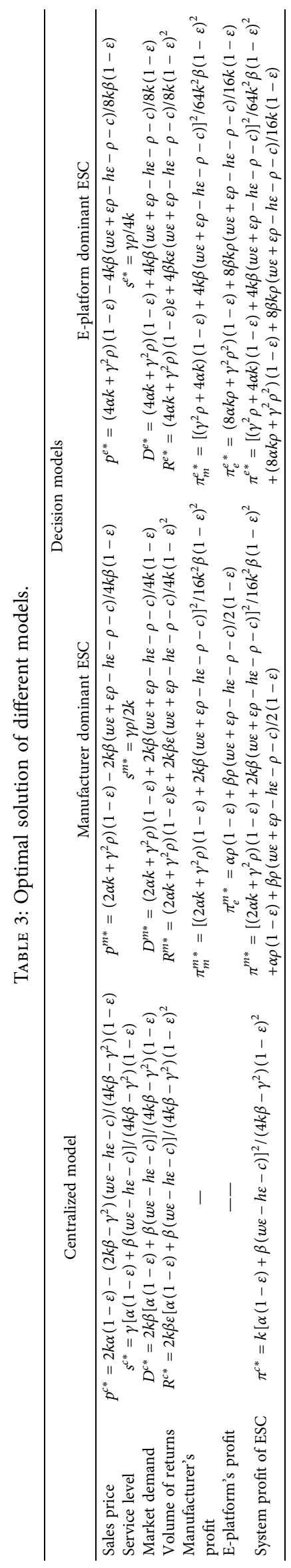


profits from increased costs, the first response from the manufacturer is to increase the products' sales price. This behavior will lead some pricesensitive consumers to switch to other homogeneous products, thereby reducing market demand. At this point, the change direction of the volume of returns is not consistent with the market demand but showing an upward trend. This indicates that the increase in returns is primarily caused by higher return rates, which is a vicious increase in returns. In addition, while the manufacturer attempted to increase sales prices to increase profits, the additional profits generated do not cover profit losses due to declining market demand, which ultimately leads to lower manufacturer profits. Meanwhile, due to the e-platform' profit determined by the market demand, the decrease in demand also makes the e-platform profit decline.

(2) Under decentralized models, the return rate does not affect service level. This is because the e-platform's service level under decentralized models is determined by the level of commission, which is established when manufacturer enters e-platform and is not affected by the decision results. Under the centralized model, the service level declines with higher return rates, because e-platform and manufacturer make decisions to maximize system profits at this point. When the product return rate increases, the ESC system, in order to minimize losses, will reduce the service cost of the e-platform, which will lead to a lower service level.

Conclusion 2. Optimal decisions are affected by the returned product's average salvage value of $w$ as follows:

(1) $p^{c *}, p^{m *}$, and $p^{e *}$ are negatively related to $w ; D^{c *}$, $D^{m *}$, and $D^{e *}$ are positively related to $w ; R^{c *}, R^{m *}$, and $R^{e *}$ are positively related to $w ; \pi_{m}^{m *}, \pi_{e}^{m *}, \pi_{m}^{e *}$, $\pi_{e}^{e *}, \pi^{c *}, \pi^{m *}$, and $\pi^{e *}$ are positively related to $w$.

(2) $s^{c *}$ is positively related to $w$, but $s^{m *}$ and $s^{e *}$ are independent of $w$.

The proof is similar to Conclusion 1 .

According to Conclusion 2, one has the following:

(1) In ESC, higher salvage value of returned products results in lower sales prices, higher market demand, and volume of returns, which ultimately results in higher profits for manufacturer, e-platform, and ESC system. This is because of the lower salvage value; the greater the profit loss caused by the return behavior to the manufacturer, the higher the sales price to compensate for the manufacturer's profit loss. Conversely, the higher the salvage value, the more the manufacturers cut prices to expand sales volumes. With a stable return rate, an increase in market demand will also lead to an uptick in the volume of returns, but this benign rise of returns will not reduce manufacturer profits. Meanwhile, both manufacturers and e-platforms will be more profitable due to the increase in the actual sales of products.

(2) Under decentralized models, the returned product's salvage value has no impact on the service level of e-platform. Differently, the service level increases with increasing salvage value in the centralized model. This is because, in the actual ESC operation, the commission is made in advance of the decision-making, and e-platform has no motivation to increase service inputs in the decision-making process. But when e-platforms work closely with manufacturers to reach centralized decisions, they make decisions to maximize ESC profits. At this point, the higher salvage value of the returned products brings higher profits to ESC, and the ESC system has an incentive to improve the service level.

Conclusion 3. Optimal decisions are affected by the return handling cost $h$ as follows:

(1) $p^{c *}, p^{m *}$, and $p^{e *}$ are positively related to $h ; D^{c *}$, $D^{m *}$, and $D^{e *}$ are negatively related to $h ; R^{c *}, R^{m *}$, and $R^{e *}$ are negatively related to $h ; \pi_{m}^{m *}, \pi_{e}^{m *}, \pi_{m}^{e *}$, $\pi_{e}^{e *}, \pi^{c *}, \pi^{m *}$, and $\pi^{e *}$ are negatively related to $h$.

(2) $s^{c *}$ is negatively related to $h$, but $s^{m *}$ and $s^{e *}$ are independent of $h$.

The proof is similar to Conclusion 1.

According to Conclusion 3, one has the following:

(1) In ESC, higher return handling cost leads to higher sales prices, lower market demand, and volume of returns, which ultimately results in lower profits for manufacturer, e-platform, and ESC system. This shows that when the return handling cost is higher, manufacturer will transfer part of the return handling cost to consumers by raising sales price, which is unfavorable to consumers. This "cost transfer" phenomenon will cause a reduction in market demand, which will lead to a nonbenign reduction in the volume of returns. Further, lower market demand will also lead to lower profits for ESC members.

(2) Under decentralized models, the return handling costs have no impact on the service level of e-platform. Differently, the service level decreases with increasing the return handling costs in the centralized model. This is the same as the genesis of Conclusions 1 and 2; that is, the service level is only affected by commissions, which are designated in advance of decisions. However, under centralized decision-making, ESCs will reduce the service level to avoid further profit loss due to lower market demand and higher production operating costs in ESC. 
Conclusion 4. Optimal decisions are affected by the consumers' service quality preferences $\gamma$ as follows:

(1) $p^{c *}, p^{m *}, p^{e *}, s^{m *}, s^{e *}, s^{c *}, D^{c *}, D^{m *}, D^{e *}, R^{c *}, R^{m *}$, $R^{e *}, \pi^{c *}, \pi^{m *}$, and $\pi^{e *}$ are positively related to $\gamma$. Meanwhile, $\left(\partial s^{c *} / \partial \gamma\right)>\left(\partial s^{m *} / \partial \gamma\right)>\left(\partial s^{e *} / \partial \gamma\right)$.

(2) $\pi_{m}^{m *}$ and $\pi_{m}^{e *}$ are positively correlated with $\gamma$, and $\left(\partial \pi_{m}^{m *} / \partial \gamma\right)>\left(\partial \pi_{m}^{e *} / \partial \gamma\right) ; \pi_{e}^{e *}$ is positively correlated with $\gamma$, but $\pi_{e}^{m *}$ is not affected by $\gamma$.

The proof is similar to Conclusion 1 .

According to Conclusion 4, one has the following:

(1) Regardless of decision-making models, increased consumers' service quality preferences will result in the increased sales price, service level, market demand, and volume of returns, ultimately increasing the profitability of the ESC. This is due to the direct link between consumers' service quality preferences and the e-platform's user scale. Thus, e-platform improving her service level can increase the likelihood of consumers buying through e-platform. Further, the increase in market demand caused a positive growth in the volume of returns. At the same time, increased consumer service sensitivity makes consumers relatively less price-sensitive, so the manufacturer will raise sales prices to capture additional revenue. Ultimately, the profitability of the ESC system has been enhanced by the expansion of market demand and increased sales prices. Additionally, the service level on centralized decisionmaking is the most sensitive to the market response, which is the same as previous conclusions. It should be noted that the service level when manufacturers dominate ESC is more catering to consumers' service quality preferences than that when e-platforms dominate ESC. This is because ESC dominators prefer to ask followers to make efforts to improve supply chain performance, rather than to increase their own input. As a result, the dominant manufacturer will require the e-platform to increase service investments in response to increased consumers' service quality preferences. And when the e-platform dominates ESC, she prefers to attract consumers by asking the manufacturer to cut sales prices.

(2) Under both channel power structures, the improvement in consumers' service preferences can boost manufacturer's profit, and higher profit growth for manufacturer is obtained when he dominates ESC. However, for the e-platform, she cannot profit from consumers' service quality preferences when the manufacturer dominates ESC. Only when the e-platform has channel dominance can she increase revenue from increased consumer's service preferences. Combined with Conclusion 4 (1), it can be found that the following e-platform increases her service investment, but in allocating the additional profits from the increased consumer's service preferences, she can only receive the part equivalent to her increased service cost, which cannot achieve the profit increase for the following e-platform. For the manufacturer, he can profit from consumer's service quality preferences under both power structures. This is because the manufacturer does not need to put up money for increased service level but benefits from increased market demand. Of course, the larger the manufacturer's channel power, the greater his profit from increased consumer's service quality preferences.

Conclusion 5. The results of the equilibrium solution comparison are as follows:

(1) $p^{c *}>p^{m *}>p^{e *}, \quad s^{c *}>s^{m *}>s^{e *}, \quad \pi_{m}^{m *}>\pi_{m}^{e *}, \quad$ and $\pi_{e}^{m *}<\pi_{e}^{e *}$

(2) $D^{m *}>D^{e *}, R^{m *}>R^{e *}$, and $\pi^{c *}>\pi^{m *}>\pi^{e *}$.

See Appendix B for proof.

According to Conclusion 5, one has the following:

(1) Product's price and e-platform's service level are highest in centralized decision-making and lowest under decentralized decision-making with dominant e-platform. That is in accordance with previous findings $[33,34]$ that the dominant manufacturers will use priority decision-making power to make decisions that maximize their own benefits. The manufacturer can use his dominance to raise sales price and force e-platform to improve service level. Similarly, when e-platform dominates ESC, e-platform will decrease the service level to reduce her operating costs. Not only that, but she will also induce manufacturer to cut sales prices, ultimately achieving the goal of expanding the customer base and increasing profits.

In summary, the dominant enterprise, whether it is the manufacturer or the e-platform, will have a decision-making advantage in cooperation, which can increase their own profits. Therefore, ESC participants are reluctant to lose dominant power, which will result in a power struggle between them and even further lead to the breakdown of partnership and the disruption of ESC. As an example, China's liquor e-platform, Jiuxian (http://www.jiuxian.com), offered Maotai Liquor at below-market prices without permission, prompting dissatisfaction among Maotai manufacturers, who eventually stopped selling their products on Jiuxian (http://it.southcn.com/9/201403/29/content_96281574.htm). Apparently, the strife between Maotai manufacturers and Jiuxian stems from the struggle for dominant power.

(2) Market demand and the volume of returns are higher in the manufacturer-dominated decentralized model. The increased service level is an important 
reason for higher market demand when the manufacturer dominates ESC. Meanwhile, when product return rates are stable, elevated demand will increase the volume of returns, but this benign increase in returns has no negative impact on either ESC members or system profits. Therefore, the system is more profitable when the manufacturer dominates ESC. Additionally, the centralized model prevents double marginal effects, so the system profit reaches the highest under this model.

\section{Extension: Consumer Utility Analysis}

We have also noticed that more and more consumers are forming return habits [16]. Is the act of returns necessarily beneficial to consumer themselves? Do ESC's different decision-making models and power structures affect consumer utility? How does the e-platform's service level affect consumer utility? To address the above issues, an extended model of consumer utility is proposed in this paper.

Suppose that when the customer determines to purchase the product, he will first make a judgment about the product's basic utility $\theta v$, and then he needs to pay $p^{i *}(i=$ $c, m, e)$ through the e-platform for the product, where $\theta(0 \leq \theta \leq 1)$ represents the probability of suitable products and $v(v \geq 0)$ is per-unit-of-product valuation, which is consistent with the assumptions of Zhang et al. [21] and Yan et al. [35].

The service level affects consumer utility by affecting the consumer shopping experience $[80,81]$. Therefore, drawing on Yan et al. [35], the positive impact of service level on consumer utility is $\gamma s$.

Meanwhile, returns will incur implicit costs to consumers, including psychological costs of consumer waiting times for online shopping, price losses resulting from missed promotions, time costs for repurchasing, and so on. Following Wang and Huang [82] and Zhang et al. [83], the paper assumes that $t(t \geq 0)$ is the unit implicit cost of the consumer's return (hereafter called consumer return cost).

Based on assumptions in Section 3, the manufacturer will provide a full refund to consumers who file a return request and will bear the corresponding return costs. In the hypothesis of $\mathrm{Ma}$ et al. [16], there are two parts to the consumer utility created by unsuitable products: the first part is the refund $\varepsilon(1-\theta) p^{i *}$ generated by the returned goods and the other part is the residual value $(1-\varepsilon)(1-\theta) g$ of the unreturned goods (where $g$ represents the average revenue gained from the resale of the unsuitable goods and $0<g<v)$. At this point, the consumer return cost is expressed as $\varepsilon(1-\theta) t$ in the utility function, and the consumer utility is

$$
U^{i *}=\theta v-p^{i *}+\varepsilon(1-\theta)\left(p^{i *}-t\right)+(1-\varepsilon)(1-\theta) g+\gamma s^{i *}, \quad i=c, m, e
$$

In this paper, as a simplified model, it is assumed that consumers will choose to return the product when they think it is not suitable; namely,

$$
U^{i *}=(1-\varepsilon) v-p^{i *}+\varepsilon\left(p^{i *}-t\right)+\gamma s^{i *}, \quad i=c, m, e .
$$

By comparing the consumer utility under the above decision-making models, the following conclusions can be obtained.

Conclusion 6. The impact of the return rate $\varepsilon$ on consumer utility depends on the decision mode and consumer's return cost $t$ (the consumer's return cost thresholds for centralized model, manufacturer-led decentralized model, and e-platform-led decentralized model are $\left.t_{0}^{i *}, i=c, m, e\right)$.

(1) Under centralized model, when $t<t_{0}^{c *}$, the consumer utility first grows and then declines as $\varepsilon$ increases, with the maximum consumer utility obtained at $\varepsilon=\varepsilon_{0}$, where $t_{0}^{c *}=\left[2 k \alpha-\left(2 k \beta-\gamma^{2}\right)(h+v-w)-\right.$ $2 k \beta v](1-\varepsilon)^{2}-(c+h-w) \beta \gamma^{2} /\left(4 k \beta-\gamma^{2}\right)(1-\varepsilon)^{2}$. When $t>t_{0}^{c *}$, the consumer utility decreases with the increase of $\varepsilon$.

(2) Under decentralized model, when $t<t_{0}^{i *}$, the consumer utility increases with $\varepsilon$. When $t>t_{0}^{i *}$, the consumer utility decreases with $\varepsilon$, where $t_{0}^{m *}=\gamma^{2} \rho+$ $2 k[\alpha+\beta(w+\rho-h-2 v)] / 4 k \beta$ and $t_{0}^{e *}=\gamma^{2} \rho+4$ $k[\alpha+\beta(-h-2 v+w+\rho)] / 8 k \beta$.
(3) $t_{0}^{c *}>t_{0}^{m *}>t_{0}^{e *}$.

See Appendix C for proof.

According to Conclusion 6, one has the following:

(1) Under the centralized model, if consumer return cost is low, consumer's utility first rises and then falls as return rate increases. On one hand, it is shown that return behavior is not always beneficial to consumers in the context of centralized decision-making achieved by ESC. Consumers can only profit from return behavior if the return rate is below a defined level. On the other hand, this indicates that consumers have an incentive not to engage in malicious returns. And when the ESC achieves coordination, consumers will voluntarily maintain the return rate at a certain level to maximize their own utility. If consumer return cost is higher, the return behavior will reduce the consumer's utility. At this point, ESC members should ensure the authenticity of product descriptions on the platform and guarantee product quality to minimize consumer returns, which can reduce the loss of customer utility.

(2) Under decentralized models, when consumer return cost is low, consumer utility is positively related to product return rate, and conversely, consumer utility is negatively related to return rate. Returns can increase consumers' fault tolerance when purchasing 
goods and give them shopping security. However, when the consumer return cost is high, consumers will suffer a loss of utility from their return behavior. As an example, during China's Double 11 Shopping Festival, the Taobao will offer a 7-day no-excuse return service and freight insurance. However, many consumers still feel a loss of utility from returns, which is due to the high consumer return cost at that time. On the one hand, the dramatic increase in orders during the Double 11 period has caused logistics delays, exacerbating the hidden costs of consumer logistics waiting. On the other hand, after the return of the product, consumers can no longer enjoy the Double 11 promotional activities, which also increases the return cost of consumers.

(3) Consumers are most likely to benefit from returns when decisions are made centrally, and consumers are more likely to benefit from returns in decentralized decision where manufacturer dominates ESC than where e-platform dominates ESC. This is because ESC is most efficient under the centralized model, where members respond quickly to consumer returns and the service reaches the highest. In addition, consumers are more likely to profit from returns when manufacturers dominate ESCs compared to e-platforms, which is caused by higher service levels at this time.

Conclusion 7. When $2 \beta+\varepsilon-1>0, U^{m *}, U^{e *}$, and $U^{c *}$ are positively related to $\gamma$. When $2 \beta+\varepsilon-1<0, U^{m *}, U^{e *}$, and $U^{c *}$ are negatively related to $\gamma$.

The proof is similar to Conclusion 6 .

On the one hand, if the product return is low, higher consumer's service quality preferences will enhance consumer utility when consumers have a high price preference. This reflects a positive link between the two types of consumer preferences, and an ESC with a lower return rate should meet consumer demands in terms of both price and service. Additionally, when the volume of returns is high, increased consumer's service quality preferences can have a positive impact on consumer utility even if consumers have lower price preferences. This is because ESC has a full refund policy; consumers who return goods cannot get a utility boost from the price, only from the service in the purchase. At this point, the higher the consumer's service quality preference, the greater the consumer utility.

Conclusion 8. $U^{c *}>\max \left\{U^{m *}, U^{e *}\right\}$. When $2 \beta+\varepsilon-1>0$, $U^{m *}>U^{e *}$.

The proof is similar to Conclusion 5 .

Consumer utility is highest under the centralized model, while consumer utility under different channel powers of decentralized models depends on both consumers' price preferences and return rate. This is because under the centralized model, ESC members work together to enhance the consumer's shopping experience to compensate for the utility loss. For decentralized models, when return rate is stable and consumer's price preference is high, greater consumer utility is obtained when manufacturer dominates ESC. This is due to higher return prices (selling prices) in the manufacturer-dominated ESC model, which allows consumers to derive more utility from the act of returns. When consumer's price preference is stable and return rate is high, greater consumer utility is obtained when manufacturer dominates ESC. This is because the benefits for returning consumers are mainly derived from the service of the e-platform, while service level is higher when manufacturer dominates ESC by Conclusions 4 and 5 .

It can be concluded from Conclusions 1-8 that centralized decision-making can simultaneously maximize ESC efficiency and consumer utility. However, centralized decision-making needs to be achieved through the coordination mechanism. Therefore, in Section 6 of this paper, the return handling costs and commissions are considered, and new coordination mechanisms are designed to optimize ESC profits and maximize consumer utility.

\section{Coordination Mechanism}

In this section, the "return cost-sharing and commission readjusting" contract is designed to deliver Pareto improvements in decentralized decisions. The concept of contract is that the manufacturer pays higher commissions to the e-platform to cement the ESC partnership and increase the e-platform's profitability. Meanwhile, the e-platform proactively shares a portion of manufacturers' return handling costs to reduce the financial pressure on manufacturers from consumer returns. In the "return costsharing and commission readjusting" contract, assume that manufacturer pays commission $\bar{\rho}$ and e-platform shares the return processing costs in proportion $u$.

Manufacturer profit function:

$$
\bar{\pi}_{m}=p D-\bar{\rho} D+w \varepsilon Q-c Q-(1-u) h \varepsilon Q .
$$

E-platform profit function:

$$
\bar{\pi}_{e}=\bar{\rho} D-k s^{2}-u h \varepsilon Q .
$$

Conclusion 9. Under the "return cost-sharing and commission readjusting" contact, if $(\bar{\rho}, u)$ satisfies $\left\{\begin{array}{l}\bar{\rho}=(1-\varphi) p+(1-\varphi)(w \varepsilon-c) / 1-\varepsilon+\varphi k s^{2} / D, 0<\varphi<1, \\ u=(1-\varphi)\end{array}\right.$ the contract can achieve ESC coordination, in which $\varphi$ is the coordination factor, which indicates the bargaining power of manufacturer. The larger $\varphi$, the more the profit manufacturer shares after coordination and the less the profit e-platform shares and vice versa.

See Appendix D for proof.

To ensure the effectiveness of coordination, the feasible conditions of the compact are explored as follows:

(1) Under the decentralized model with the dominant manufacturer, the condition for acceptance of "return cost-sharing and commission readjusting" 
contract by manufacturer and e-platform is as follows: the profit of both parties after coordination is not less than their profit before coordination; that is, $\bar{\pi}_{m} \geq \pi_{m}^{m *}, \bar{\pi}_{e} \geq \pi_{e}^{m *}$ must be guaranteed. The collation gives that the effective range of $\varphi$ is $\left(\pi_{m}^{m *} / \pi^{c *}\right) \leq \varphi \leq 1-\left(\pi_{e}^{m *} / \pi^{c *}\right)$. So $\varphi$ meets

$$
\begin{array}{r}
\varphi \in\left[\frac{\left(4 k \beta-\gamma^{2}\right)\left[\left(\gamma^{2} \rho+2 k \alpha\right)(1-\varepsilon)+2 k \beta(w \varepsilon+\rho \varepsilon-h \varepsilon-c-\rho)\right]^{2}}{16 k^{3} \beta[\alpha(1-\varepsilon)+\beta(w \varepsilon-h \varepsilon-c)]^{2}},\right. \\
\left.1-\frac{\left(4 k \beta-\gamma^{2}\right)(1-\varepsilon) \rho[\alpha(1-\varepsilon)+\beta(w \varepsilon+\rho \varepsilon-h \varepsilon-c-\rho)]}{2 k[\alpha(1-\varepsilon)+\beta(w \varepsilon-h \varepsilon-c)]^{2}}\right] .
\end{array}
$$

(2) Under decentralized decision-making with dominant e-platform, coordinated profits of ESC participants are no less than their precoordination profits; that is, $\bar{\pi}_{m} \geq \pi_{m}^{e *}, \bar{\pi}_{e} \geq \pi_{e}^{e *}$ must be guaranteed. The collation gives that the effective range of $\varphi$ is $\left(\pi_{m}^{e *} / \pi^{c *}\right) \leq \varphi \leq 1-\left(\pi_{e}^{e *} / \pi^{c *}\right)$. So $\varphi$ also meets

$$
\begin{aligned}
& \varphi \in\left[\frac{\left[\left(\gamma^{2} \rho+4 k \alpha\right)(1-\varepsilon)+4 k \beta(w \varepsilon+\rho \varepsilon-h \varepsilon-c-\rho)\right]^{2}\left(4 k \beta-\gamma^{2}\right)}{64 k^{3} \beta[\alpha(1-\varepsilon)+\beta(w \varepsilon-h \varepsilon-c)]^{2}},\right. \\
&\left.1-\frac{\left(\rho^{2} \gamma^{2}+8 k \alpha \rho\right)(1-\varepsilon)+8 k \beta \rho(w \varepsilon+\rho \varepsilon-h \varepsilon-c-\rho)\left(4 k \beta-\gamma^{2}\right)(1-\varepsilon)}{16 k^{2}[\alpha(1-\varepsilon)+\beta(w \varepsilon-h \varepsilon-c)]^{2}}\right] .
\end{aligned}
$$

Proposition 1. $u$ is negatively correlated with $\varphi$. The proof is similar to Conclusion 1.

Under the coordination mechanism, as $u$ increases, the proportion $\varphi$ of the system profits shared by manufacturer will decrease, and the proportion $1-\varphi$ of the system profits shared by e-platform will increase. That is, the higher the return handling costs borne by the e-platform, the higher her share of the ESC profits. Therefore, by using the contract of "return cost-sharing and commission readjusting," the e-platform's initiative and enthusiasm to share the manufacturer's return handling costs will be greatly improved, and the e-platform's commitment to return costs has increased her own profits. For manufacturer, the e-platform's behavior of sharing the return cost eases the financial burden on the manufacturer, which strengthens his willingness to cooperate with e-platform. The above fully illustrate the practicality of the "joint commission return cost-sharing" contract.

\section{Numerical Analysis}

\subsection{Numerical Analysis of Models}

7.1.1. Numerical Analysis of Optimal Decisions. To further analyze equilibrium solutions, numerical examples are used in this section. Based on Shen and Wang [84] and Wang et al. [68], this paper assumes that $\alpha=500, \beta=1$, $\gamma=0.5, k=0.5, c=100, w=60, h=10$, and $\rho=20$. This subsection discusses the effect of return rate on ESC decisions and profit, taking $\varepsilon$ as the dependent variable and $\varepsilon \in[0.2,0.8]$. The results for different models are presented in Figures 2-4.
Conclusions 1-5 can be verified by Figures 2-4, and the following conclusions can also be drawn:

(1) As the return rate increases, sales price, market demand, the volume of returns, and profits for manufacturer, e-platform, and system change more and more rapidly. This is because when the return rate increases, the manufacturer compensates for lost profits by raising sales price. The higher the return rate, the more the profit that needs to be made up through higher prices, but the fewer the consumers that are bearing the higher prices. This causes the sales price to rise sharply, which results in a steep decline in market demand. Ultimately, this vicious cycle leads to a drastic increase in lost profits for the manufacturer, the e-platforms, and the ESC system.

(2) Compared to decentralized decisions, the slightly higher sales price but much higher service level under the centralized model leads to market demand and ESC profits reach highest under centralized decisions. Furthermore, as the return rate rises, the gap between centralized and decentralized decisions on demand and ESC profits gradually shrinks, which is caused by consumer returns shrinking the profit space of ESC.

From the conclusions and numerical simulation results, it can also be concluded that the manufacturer-led decentralized decision is better than e-platform-led decentralized decision. That is, the power structure dominated by e-platform under decentralized decision is not conducive to the operation of ESC. But in reality, there are many powerful e-platforms with channel power, such as Amazon (http:// www.amazon.com), ebay (http://www.ebay.com), and Tmall 


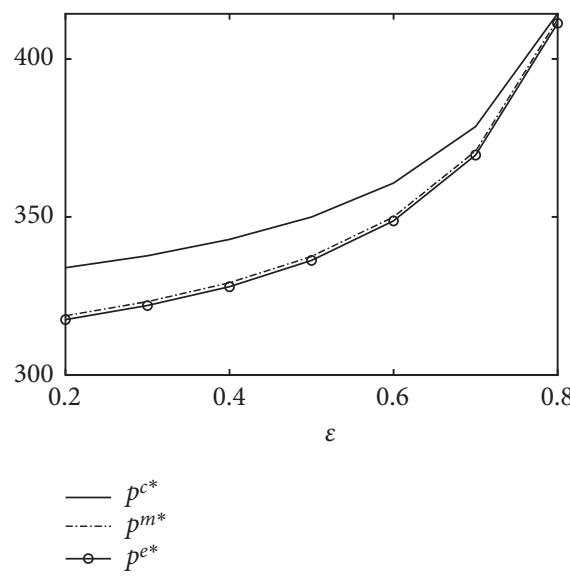

(a)

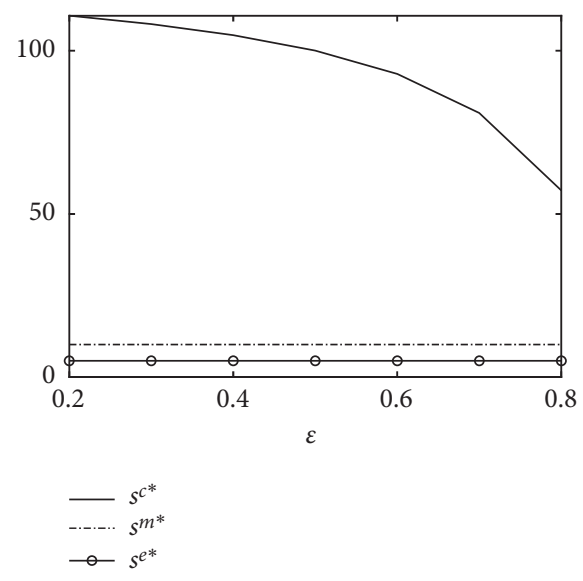

(b)

Figure 2: Changes in Decision Variables with $\varepsilon$. (a) Changes in sales price. (b) Changes in service level.

(http://www.Tmall.com). The reasons for this situation are as follows.

The rapidly developing Internet economy has gradually made e-platforms because of reliable information centers and trading platforms. Currently, many powerful e-platforms have formed a loyal customer base, which becomes their advantage in the channel competition. In addition, the role of e-platforms is gradually coming to the fore as manufacturers can greatly reduce the intermediate costs of sales through e-platforms for direct sales. For manufacturers, most of them cannot afford to build their own online sales channels due to high costs and long construction cycles, so they have to choose to enter e-platforms to cater to online consumers.

However, the increased dominance of e-platform is detrimental to ESC's long-term growth. Therefore, the following manufacturers should enhance their channel power through certain strategies, such as enhancing their brand power, building a good corporate image, strengthening communication with e-platforms, and seeking ways to grasp market information. From Conclusion 5, when the manufacturer takes control of the channel, the volume of product returns is higher, although the system operates more efficiently. Therefore, for manufacturers in control of the channel, improving quality management systems, enhancing product compatibility and ease of use, and working to reduce the volume of product returns are urgent issues to be addressed.

Meanwhile, the study also finds that higher return rates can set off a vicious cycle that hurts both consumers and ESCs. Therefore, manufacturers and e-platforms need to cooperate closely to ensure that product return rates are kept within a low range. For manufacturers, on the one hand, they need to control the production, storage, and transportation of their products more carefully to prevent product quality problems. On the other hand, they also need to stabilize sales prices within a reasonable range to meet consumers' price preferences. For e-platforms, they need to enhance service levels to improve consumer utility during shopping and return process. As an example, e-platforms such as Tmall and JD provide protection services such as "lightning delivery" and "online dispute resolution platform for transactions."

7.1.2. Numerical Analysis of Consumer Utility. Considering consumer utility, assume that $\alpha=400, \beta=1$, $\gamma=2, k=2, c=100, w=60, h=10, \rho=20, v=150$, and $\varepsilon \in[0.2,0.8]$. With $t=50$ and $t=100$, respectively, consumer utility varies with return rate as shown in Figure 5.

Further, assume $\alpha=500, k=2, c=100, w=60, h=10$, $\rho=20, v=1000$, and $t=20$, taking $\gamma$ as the dependent variable and $\gamma \in[0.1,0.3]$. Suppose $2 \beta+\varepsilon-1<0$ (taking $\beta=0.3 ; \varepsilon=0.1$ ) and $2 \beta+\varepsilon-1>0$ (taking $\beta=1 ; \varepsilon=0.1$ ), respectively; consumer utility varies with consumer's service quality preferences as shown in Figure 6.

Conclusions 6-8 are validated in Figures 5 and 6, and it can be seen that consumer utility is influenced by the consumers' return costs and the consumers' service quality sensitivity. Consumer utility is more significantly influenced by consumers' service quality sensitivity when manufacturer dominates ESC. Moreover, consumer utility is consistently highest under centralized model, and the gap of consumer utility between centralized model and decentralized models is large. Thus, centralized decision-making is beneficial for both ESCs and consumers.

7.2. Numerical Analysis of the Coordination Mechanism. Assuming $\alpha=500, \beta=1, \gamma=0.5, k=0.5, c=30, w=60$, $h=10, \rho=20$, and $\varepsilon=0.3$, the following results can be obtained by calculation:

(1) Under the decentralized model with the dominant manufacturer, before coordination of "return costsharing and commission readjusting," the commission is $\rho=20$, manufacturer's profit is $\pi_{m}^{m *}=53725$, and e-platform's profit is $\pi_{e}^{m *}=4586$. After coordination, the range of change in commission, manufacturer's profit, and e-platform's profit is $\bar{\rho} \in(53.67,78.03)$, $\pi_{m}^{m *} \in(53659,60202)$, and $\pi_{e}^{m *} \in(5235,11779)$, 


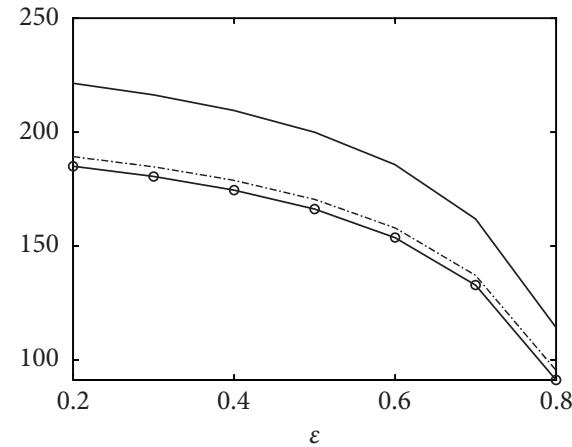

$-D^{c *}$
$-\cdots D^{m^{*}}$
$\multimap D^{e^{*}}$

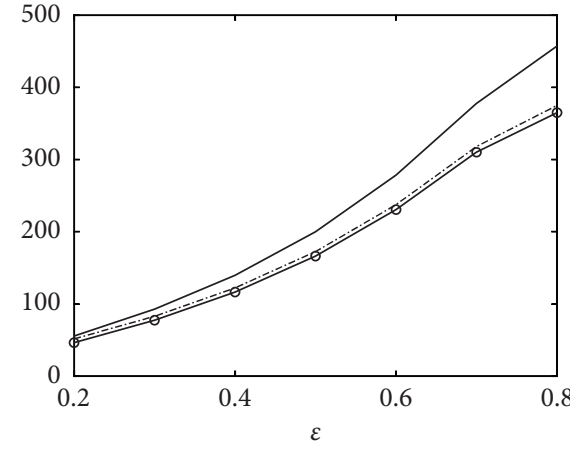

$-R^{c^{*}}$

-.... $R^{m^{*}}$

$\rightarrow R^{e^{*}}$

(a)

(b)

FIgURE 3: Changes in market demand and volume of returns with $\varepsilon$. (a) Changes in market demand. (b) Changes in volume of returns.
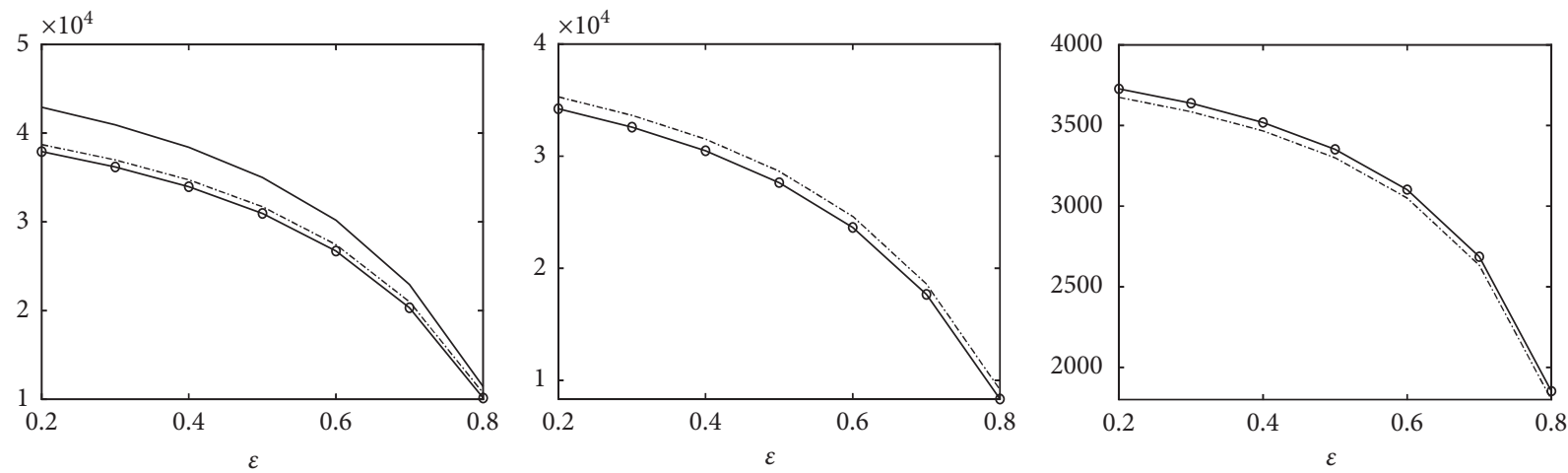

$$
\begin{aligned}
& -\pi^{c^{*}} \\
& -\cdots \cdots \pi^{m^{*}} \\
& -0 \pi^{e^{*}}
\end{aligned}
$$$$
\text { -..... } \pi_{m}^{m *}
$$$$
\cdots \cdots \pi_{e}^{m^{*}}
$$$$
\multimap \pi_{m}^{e^{*}}
$$$$
\rightarrow \pi_{e}^{e^{*}}
$$

(a)

(b)

(c)

FIgURE 4: Changes in profits with $\varepsilon$. (a) Changes in ESC's profit. (b) Changes in manufacturer's profit. (c) Changes in E-platform profit.
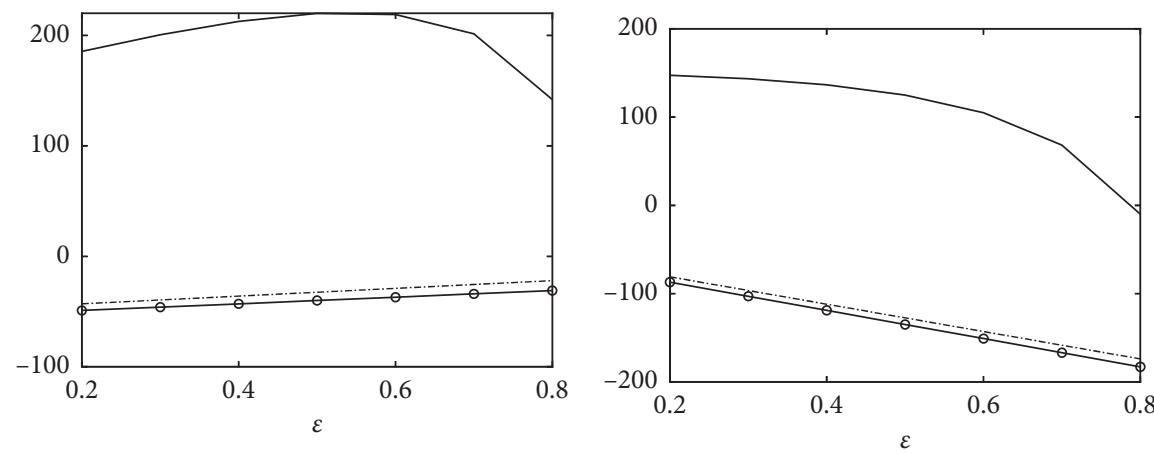

$$
\begin{aligned}
& -U^{c^{*}} \\
& -\cdots U^{m *} \\
& -U^{e^{*}}
\end{aligned}
$$$$
\begin{aligned}
& -U^{c^{*}} \\
& -\cdots U^{m^{*}} \\
& \rightarrow U^{e^{*}}
\end{aligned}
$$

(a)

(b)

FIgUre 5: Changes in consumer utility with $\varepsilon$. (a) $t=50$. (b) $t=100$. 

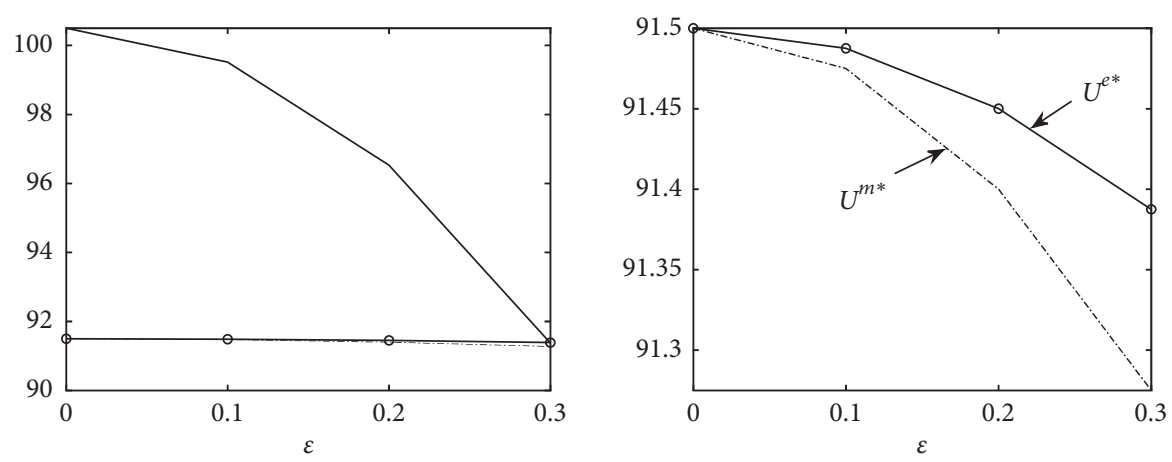

$$
\begin{aligned}
& -U^{c^{*}} \\
& \cdots U^{m *} \\
& -U^{e^{*}}
\end{aligned}
$$

(a)
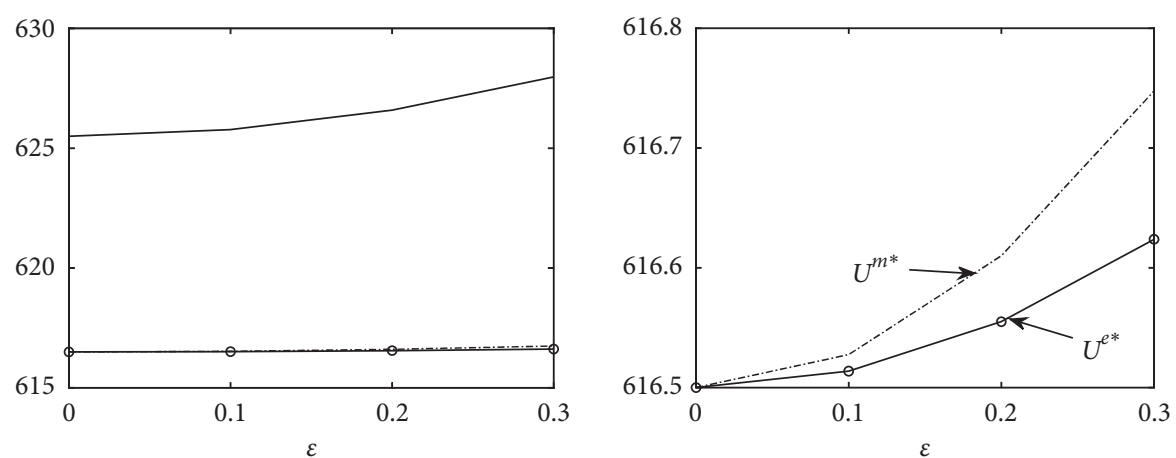

$$
\begin{aligned}
& -U^{c^{*}} \\
& -U^{m *} \\
& -U^{e^{*}}
\end{aligned}
$$

(b)

FIgURE 6: Changes in consumer utility with $\gamma$. (a) $2 \beta+\varepsilon-1<0(\beta=0.3 ; \varepsilon=0.1)$. (b) $2 \beta+\varepsilon-1>0(\beta=1 ; \varepsilon=0.1)$.

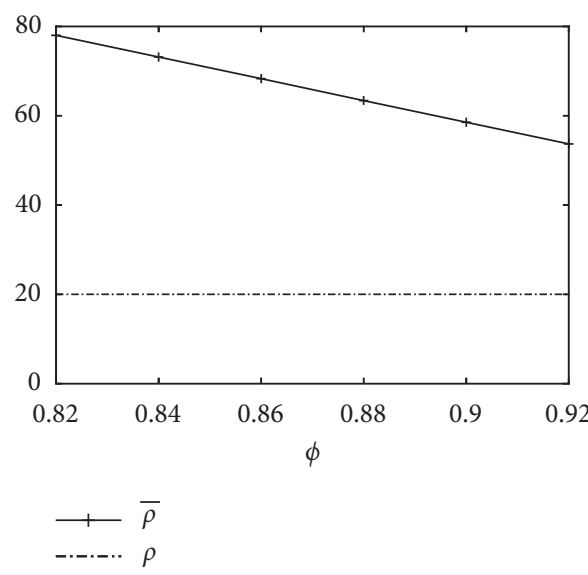

(a)

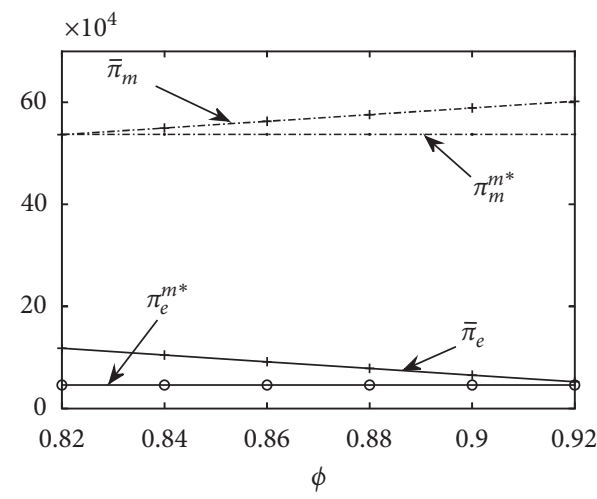

$\longrightarrow \bar{\rho}$

(b)

Figure 7: Comparison before and after coordination with dominant manufacturer. (a) Changes in commission. (b) Changes in profits. 


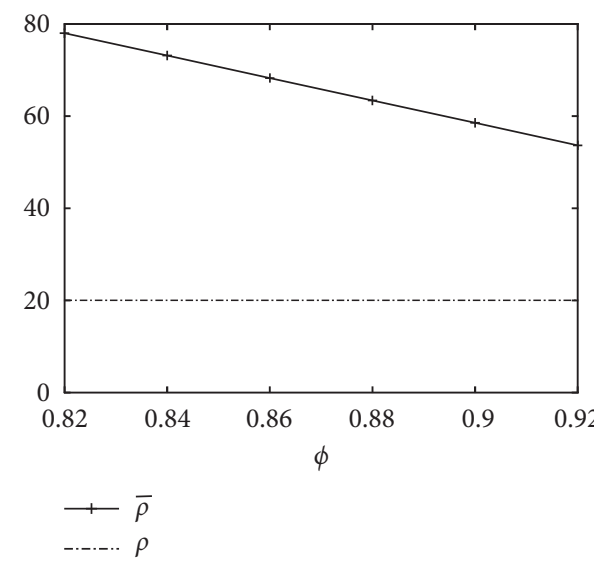

(a)

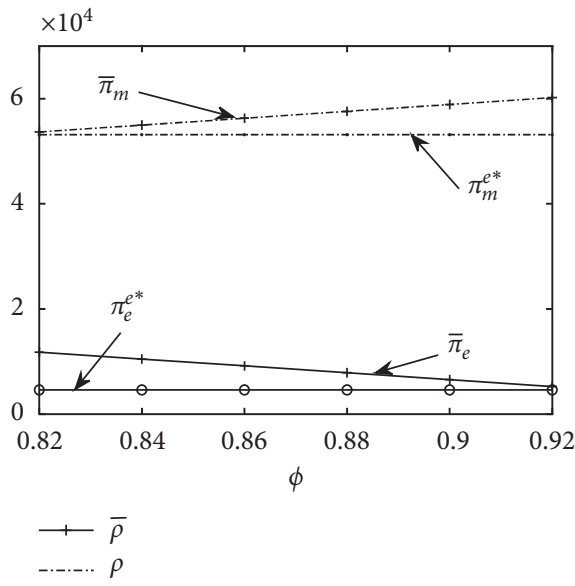

(b)

FIgURE 8: Comparison before and after coordination with dominant E-platform. (a) Changes in commission. (b) Changes in profits.

respectively. As the coordination coefficient $\varphi(\varphi \in(0.82,0.92))$ increases, the change in commission and member profits before and after coordination is shown in Figure 7.

(2) Under the decentralized model with dominant e-platform, before coordination, commission, manufacture's profit, and e-platform's profit are $\rho=20, \pi_{m}^{e *}=53147$, and $\pi_{e}^{e *}=4598$, respectively. After coordination, the range of change in commission, manufacturer's profit, and e-platform's profit is $\bar{\rho} \in(53.67,78.03), \pi_{m}^{m *} \in(53659,60202)$, and $\pi_{e}^{m *} \in(5235,11779)$, respectively. As the coordination coefficient $\varphi(\varphi \in(0.82,0.92))$ increases, the change in commission and member profits before and after coordination is shown in Figure 8. and 8 .

The following conclusions can be drawn from Figures 7

As coordination factor $\varphi$ increases, the commissions paid by manufacturer to e-platform, although gradually decreasing, are always higher than that before coordination. By adjusting commissions, ESC achieves a redistribution of profits, which demonstrates the feasibility of using commissions as a profit adjustment tool for coordination mechanisms. In addition, the profits of the e-platform after coordination, while decreasing with the increase of $\varphi$, are always higher than her profits before coordination. Likewise, manufacturers have earned higher profits through coordination.

\section{Conclusions}

Considering the serious return problems of ESCs and considering the different channel power structures, ESC composed of a manufacturer and an e-platform is constructed. The paper examines the impact of channel structures and consumer returns on ESC. Moreover, this paper establishes an extended model of consumer utility, studies the impact of return rates and consumer service preferences on consumer utility, and seeks a balance between system performance and consumer utility. Finally, the return handling cost and commissions are considered, and new coordination mechanisms are designed to optimize ESC profits and maximize consumer utility. The main conclusions are listed as follows:

(1) Consumer return rates, salvage value of returned products, and return handling cost all have significant impacts on ESC. In ESC, higher product return rates result in higher sales prices, lower market demand, and higher volume of returns, which ultimately results in lower profits for manufacturer, e-platform, and ESC system. Second, the higher the salvage value, the lower the sales price, the greater the market demand, and the more profitable the ESC. Additionally, higher return handling costs can result in higher sales price and lower market demand, which adversely affects ESC.

(2) In centralized decision-making, the service level is inversely proportional to consumer return rates and the return handling costs and proportional to the salvage value of returned products. Under decentralized decisions, return rate does not affect service level of e-platform (different from [28]). Increasing consumers' service preferences will promote product prices and service level (unlike [29]) and increase market demand and ESC profitability (unlike [30]). Moreover, the effect of consumers' service preferences on the manufacturer's profits and the e-platform's profit depends on the channel power structures. Under both channel power structures, an increase in consumers' service quality preferences can increase manufacturer's profit, and the increase in profits is greater when manufacturer dominates ESC. However, for the e-platform, she cannot profit 
from consumers' service quality preferences when the manufacturer dominates ESC.

(3) Under different power structures, the profits of the dominant enterprise are higher than the following enterprise. This is because the dominant enterprises will use priority decision-making power to make decisions that maximize their own benefits. Additionally, when the manufacturer dominates ESC, market demand and system profit are relatively high because the dominant manufacturer forces the e-platform to increase service level.

(4) The impact of the return rate on consumer utility depends on two factors: the decision-making mode and the consumers' hidden cost of returns. Under centralized decision-making, ESC efficiency optimization and consumer utility maximization can be achieved simultaneously. Under the different channel powers of decentralized decision-making, the impact of channel structure and consumer's service quality preference on consumer utility is determined by consumer's price preference and return rate. When return rate is stable and consumer's price preference is high, consumer's service quality preference will have a positive impact on consumer utility. At this time, the consumer utility is higher when the manufacturer dominates ESC.

(5) For ESCs with consumer returns, the paper uses both commissions and return handling costs as adjustment tools to design a new "return cost-sharing and commission readjusting" contract. The more e-platform pays for the handling costs, the higher the profit she earns after coordination. The contract maximizes ESC efficiency and consumer utility.

Through the conclusions of the paper, the following management insights can be presented:

(1) For manufacturers, the first step is to invest more in the technology for handling returned products to reduce the unit cost of returns, which not only meets environmental requirements but also increases the profitability of ESC. Second, manufacturers need to control the production, storage, and transportation of their products more carefully to prevent product quality problems, which can increase their channel power. Moreover, whether or not manufacturers dominate ESCs, they should not compensate for their lost profits by increasing sales prices, because this approach leads to a decrease in market demand, resulting in greater profit loss and a vicious cycle.

(2) For e-platforms, first, their service level should not be completely limited by the size of the commissions but should cater to consumer's service quality preferences to increase platform traffic and revenue. Particularly for products with high return rates, improvements in the service levels can have a significant impact on the increase in consumer utility. Second, when e-platforms dominate ESCs, they should not require manufacturers to significantly reduce their prices to attract consumers (a common phenomenon during online shopping festivals). On the contrary, e-platforms should strengthen cooperation with manufacturers, which can not only enhance their own and manufacturers' profits but also increase the utility of platform users, forming a win-win situation.

However, the paper only examines a single-stage ESC composed of a manufacturer and an e-platform. In real life, manufacturers often remanufacture and resell their returned products after receiving them, while consumers can also resell used products directly through the platform. How these behaviors affect ESC decisions and consumer utility and how coordination mechanisms can be designed to accommodate more complex operational situations will be explored in subsequent research.

\section{Appendix}

\section{A. Proof of Conclusion 1}

Proof. Under centralized model,

$$
\begin{aligned}
\frac{\partial p^{c *}}{\partial \varepsilon} & =\frac{(c+h-w)\left(2 k \beta-\gamma^{2}\right)}{\left(4 k \beta-\gamma^{2}\right)(1-\varepsilon)^{2}}>0, \\
\frac{\partial s^{c *}}{\partial \varepsilon} & =-\frac{(c+h-w) \beta \gamma}{\left(4 k \beta-\gamma^{2}\right)(1-\varepsilon)^{2}}<0, \\
\frac{\partial D^{c *}}{\partial \varepsilon} & =-\frac{2 k(c+h-w) \beta^{2}}{\left(4 k \beta-\gamma^{2}\right)(1-\varepsilon)^{2}}<0, \\
\frac{\partial R^{c *}}{\partial \varepsilon} & =\frac{2 k \beta[\alpha(1-\varepsilon)+2 \beta \varepsilon(w-h)-\beta c(1+\varepsilon)]}{\left(4 k \beta-\gamma^{2}\right)(1-\varepsilon)^{3}}>0, \\
\frac{\partial \pi^{c *}}{\partial \varepsilon} & =-\frac{2 k \beta(c+h-w)[\alpha(1-\varepsilon)+\beta \varepsilon(w-h)-\beta c]}{\left(4 k \beta-\gamma^{2}\right)(1-\varepsilon)^{3}}<0 .
\end{aligned}
$$

The same can be proved,

$$
\left(\partial p^{m *} / \partial \varepsilon\right)>0, \quad\left(\partial s^{m *} / \partial \varepsilon\right)=0, \quad\left(\partial D^{m *} / \partial \varepsilon\right)<0,
$$
$\left(\partial R^{m *} / \partial \varepsilon\right)>0,\left(\partial \pi_{m}^{m *} / \partial \varepsilon\right)<0,\left(\partial \pi_{e}^{m *} / \partial \varepsilon\right)<0,\left(\partial \pi^{m *} / \partial \varepsilon\right)<0 ;$ $\left(\partial p^{e *} / \partial \varepsilon\right)>0, \quad\left(\partial s^{e *} / \partial \varepsilon\right)=0, \quad\left(\partial D^{e *} / \partial \varepsilon\right)<0, \quad\left(\partial R^{e *} / \partial \varepsilon\right)>0$, $\left(\partial \pi_{m}^{e *} / \partial \varepsilon\right)<0,\left(\partial \pi_{e}^{e *} / \partial \varepsilon\right)<0$, and $\left(\partial \pi^{e *} / \partial \varepsilon\right)<0$.

\section{B. Proof of Conclusion 5}

Proof

(1) $p^{c *}-p^{m *}=\left(2 k \gamma^{2} \alpha+\gamma^{4} \rho-2 k \gamma^{2} \beta \rho-8 k^{2} \beta^{2} \rho\right)(1-$ $\varepsilon)+2 k \gamma^{2} \beta \varepsilon(w-h)-2 k \gamma^{2} \beta c / 4 k \beta\left(4 k \beta-\gamma^{2}\right)(1-\varepsilon)>0$, $p^{m *} / p^{e *}=2 \gamma^{2} \rho(1-\varepsilon)+4 k[\alpha(1-\varepsilon)-\beta(w \varepsilon+\rho \varepsilon-h \varepsilon-$ $c-\rho)] / \gamma^{2} \rho(1-\varepsilon)+4 k[\alpha(1-\varepsilon)-\beta(w \varepsilon+\rho \varepsilon-h \varepsilon-c-$ $\rho)]>1$; therefore, $p^{c *}>p^{m *}>p^{e *}$.

The same can be proved, $s^{c *}>s^{m *}>s^{e *}$. 
(2) $D^{c *}-D^{m *}=\left(2 k \gamma^{2} \alpha+8 k^{2} \beta^{2} \rho+\gamma^{4} \rho-6 k \gamma^{2} \beta \rho\right)(1-$ $\varepsilon)+2 k \gamma^{2} \beta \varepsilon(w-h)-2 k \gamma^{2} \beta c / 4 k\left(4 k \beta-\quad \gamma^{2}\right)(1-\varepsilon)>0$, $D^{m *}-D^{e *}=\left(\gamma^{2} \rho / 8 k\right)>0$; therefore, $D^{c *}>D^{m *}>D^{e *}$.

The same can be proved, $R^{c *}>R^{m *}>R^{e *}, \pi_{m}^{m *}>\pi_{m}^{e *}$, $\pi_{e}^{m *}<\pi_{e}^{e *}, \pi^{c *}>\pi^{m *}>\pi^{e *}$.

\section{Proof of Conclusion 6}

Proof. (1) Under centralized model,

$$
\frac{\partial U^{c *}}{\partial \varepsilon}=\frac{\left[2 k \alpha-\left(2 k \beta-\gamma^{2}\right)(h+t+v-w)-2 k \beta(t+v)\right](1-\varepsilon)^{2}-\gamma^{2} \beta(c+h-w)}{\left(4 k \beta-\gamma^{2}\right)(1-\varepsilon)^{2}},
$$

when

By solving $\left(\partial U^{c *} / \partial \varepsilon\right)=0$,

$t_{0}^{c *}<\frac{\left[2 k \alpha-\left(2 k \beta-\gamma^{2}\right)(h+v-w)-2 k \beta v\right](1-\varepsilon)^{2}-(c+h-w) \beta \gamma^{2}}{\left(4 k \beta-\gamma^{2}\right)(1-\varepsilon)^{2}}$.

$\varepsilon_{0}=\frac{2 k \alpha-(h+t+v-w)\left(2 k \beta-\gamma^{2}\right)-(t+v) 2 k \beta+\sqrt{\beta \gamma^{2}(c+h-w)\left(2 k \alpha-(h+t+v-w)\left(2 k \beta-\gamma^{2}\right)-(t+v) 2 k \beta\right)}}{2 k(\alpha-(h+2 t+2 v-w) \beta)+(h+t+v-w) \gamma^{2}}$

can be obtained.

When

$t_{0}^{c *}>\frac{\left[2 k \alpha-\left(2 k \beta-\gamma^{2}\right)(h+v-w)-2 k \beta v\right](1-\varepsilon)^{2}-(c+h-w) \beta \gamma^{2}}{\left(4 k \beta-\gamma^{2}\right)(1-\varepsilon)^{2}}$,

$\left(\partial U^{c *} / \partial \varepsilon\right)<0$.

(2) Under decentralized model,

$$
\frac{\partial U^{m *}}{\partial \varepsilon}=\frac{2 k[\alpha-\beta(h+2 t+2 v-w-\rho)]+\gamma^{2} \rho}{4 k \beta}
$$

when

$$
\begin{aligned}
t_{0}^{m *} & <\frac{\gamma^{2} \rho+2 k[\alpha+\beta(w+\rho-h-2 v)]}{4 k \beta} \\
\frac{\partial U^{m *}}{\partial \varepsilon} & >0 .
\end{aligned}
$$

when

$$
\begin{aligned}
t_{0}^{m *}>\frac{\gamma^{2} \rho+2 k[\alpha+\beta(w+\rho-h-2 v)]}{4 k \beta}, \\
\frac{\partial U^{m *}}{\partial \varepsilon}<0, \\
\frac{\partial U^{e *}}{\partial \varepsilon}=\frac{4 k[\alpha-\beta(h+2 t+2 v-w-\rho)] \gamma^{2} \rho}{8 k \beta}
\end{aligned}
$$

when

$$
\begin{aligned}
t_{0}^{e *}<\frac{\gamma^{2} \rho+4 k[\alpha+\beta(-h-2 v+w+\rho)]}{8 k \beta}, & \\
\frac{\partial U^{e *}}{\partial \varepsilon}>0 &
\end{aligned}
$$

when

$$
t_{0}^{e *}>\frac{\gamma^{2} \rho+4 k[\alpha+\beta(-h-2 v+w+\rho)]}{8 k \beta},
$$

$$
\frac{\partial U^{e *}}{\partial \varepsilon}<0
$$

(3) $t_{0}^{m *}-t_{0}^{e *}=\left(\gamma^{2} \rho / 8 k \beta\right)>0$. Similarly, $t_{0}^{c *}-t_{0}^{m *}>0$. Therefore, $t_{0}^{c *}>t_{0}^{m *}>t_{0}^{e *}$.

\section{Proof of Conclusion 9}

Proof. Under the "return cost-sharing and commission readjusting" contact, when $(\bar{\rho}, u)$ satisfies

$$
\left\{\begin{array}{l}
\bar{\rho}=(1-\varphi) p+\frac{(1-\varphi)(w \varepsilon-c)}{1-\varepsilon}+\frac{\varphi k s^{2}}{D}, \quad 0<\varphi<1, \\
u=(1-\varphi)
\end{array}\right.
$$


whether the manufacturer dominates ESC or the e-platform dominates ESC, both subjects make decisions to maximize their own profits. At this point,

$$
\begin{aligned}
\bar{\pi}_{m} & =p D-\bar{\rho} D+w \varepsilon Q-c Q-(1-u) h \varepsilon Q=\varphi \pi \\
\bar{\pi}_{e} & =\bar{\rho} D-k s^{2}-u h \varepsilon Q=(1-\varphi) \pi .
\end{aligned}
$$

It can be seen that the decision functions of manufacturer and e-platform under both power structures are affine functions of system profit. Therefore, ESC coordination can be achieved.

\section{Data Availability}

No data were used in our study.

\section{Conflicts of Interest}

The authors declare that they have no conflicts of interest.

\section{Acknowledgments}

This paper was supported by the National Natural Science Foundation of China (no. 71971129) and Shandong Province Higher Education Youth Innovation and Technology Support Program (no. 2019RWG017).

\section{References}

[1] G. Hua, S. Wang, and T. C. E. Cheng, "Price and lead time decisions in dual-channel supply chains," European Journal of Operational Research, vol. 205, no. 1, pp. 113-126, 2010.

[2] J. Zhang, P. W. Farris, J. W. Irvin, T. Kushwaha, T. J. Steenburgh, and B. A. Weitz, "Crafting integrated multichannel retailing strategies," Journal of Interactive Marketing, vol. 24, no. 2, pp. 168-180, 2010.

[3] M. Radhi and G. Zhang, "Optimal cross-channel return policy in dual-channel retailing systems," International Journal of Production Economics, vol. 210, pp. 184-198, 2019.

[4] R. Yan, "Product categories, returns policy and pricing strategy for e-marketers," Journal of Product \& Brand Management, vol. 18, no. 6, pp. 452-460, 2009.

[5] T.-M. Choi and S. Guo, "Responsive supply in fashion mass customisation systems with consumer returns," International Journal of Production Research, vol. 56, no. 10, pp. 3409-3422, 2017.

[6] W. Y. Chiang and G. E. Monahan, "Managing inventories in a two-echelon dual-channel supply chain," European Journal of Operational Research, vol. 162, no. 2, pp. 325-341, 2005.

[7] W.-y. K. Chiang, D. Chhajed, and J. D. Hess, "Direct marketing, indirect profits: a strategic analysis of dual-channel supply-chain design," Management Science, vol. 49, no. 1, pp. 1-20, 2003.

[8] Z. Zhang, S. Liu, and B. Niu, "Coordination mechanism of dual-channel closed-loop supply chains considering product quality and return," Journal of Cleaner Production, vol. 248, Article ID 119273, 2019.

[9] E. Moriarty, "Getting out from under all those ecommerce returns," June 2018, http://multichannelmerchant.com/blog/ getting-out-from-under-all-those-ecommerce-returns/.

[10] B. McWilliams, "Money-back guarantees: helping the lowquality retailer," Management Science, vol. 58, no. 8, pp. 1521-1524, 2012.
[11] B. Chen and J. Chen, "Compete in price or service?-A study of personalized pricing and money back guarantees," Journal of Retailing, vol. 93, no. 2, pp. 154-171, 2017.

[12] D. Vlachos and R. Dekker, "Return handling options and order quantities for single period products," European Journal of Operational Research, vol. 151, no. 1, pp. 38-52, 2003.

[13] V. D. R. Guide, G. C. Souza, L. N. Van Wassenhove, and J. D. Blackburn, "Time value of commercial product returns," Management Science, vol. 52, no. 8, pp. 1200-1214, 2006.

[14] A. C. de Araújo, E. M. Matsuoka, J. E. Ung, A. Massote, and M. Sampaio, "An exploratory study on the returns management process in an online retailer," International Journal of Logistics Research and Applications, vol. 21, no. 3, pp. 345-362, 2017.

[15] S. Rudolph, "E-commerce product return statistics and trends," 2016, https://www.business2community.com/ infographics/e-commerce-product-return-statistics-trendsinfographic-01505394\#hUm45j2iCV31tvsl.97.

[16] W. Ma, C. Zhao, H. Ke, and Z. Chen, "Retailer's return policy in the presence of P2P secondary market," Electronic Commerce Research and Applications, vol. 39, Article ID 100899, 2019.

[17] N. N. Bechwati and W. S. Siegal, "The impact of the prechoice process on product returns," Journal of Marketing Research, vol. 42, no. 3, pp. 358-367, 2005.

[18] X. Su, "Consumer returns policies and supply chain performance," Manufacturing \& Service Operations Management, vol. 11, no. 4, pp. 595-612, 2009.

[19] S.-P. Jeng, "Increasing customer purchase intention through product return policies: the pivotal impacts of retailer brand familiarity and product categories," Journal of Retailing and Consumer Services, vol. 39, pp. 182-189, 2017.

[20] A. Sorescu and S. M. Sorescu, "Customer satisfaction and long-term stock returns," Journal of Marketing, vol. 80, no. 5, pp. 110-115, 2016.

[21] G. Zhang, J. Shang, and P. Yildirim, "Optimal pricing for group buying with network effects," Omega, vol. 63, pp. 6982, 2016.

[22] B. Li and Y. Jiang, "Impacts of returns policy under supplier encroachment with risk-averse retailer," Journal of Retailing and Consumer Services, vol. 47, pp. 104-115, 2019.

[23] T. Suwelack, J. Hogreve, and W. D. Hoyer, "Understanding money-back guarantees: cognitive, affective, and behavioral outcomes," Journal of Retailing, vol. 87, no. 4, pp. 462-478, 2011.

[24] Z. Pei, A. Paswan, and R. Yan, "E-tailer's return policy, consumer's perception of return policy fairness and purchase intention," Journal of Retailing and Consumer Services, vol. 21, no. 3, pp. 249-257, 2014.

[25] R. Ramanathan, "An empirical analysis on the influence of risk on relationships between handling of product returns and customer loyalty in E-commerce," International Journal of Production Economics, vol. 130, no. 2, pp. 255-261, 2011.

[26] J. D. Shulman, A. T. Coughlan, and R. C. Savaskan, "Managing consumer returns in a competitive environment," Management Science, vol. 57, no. 2, pp. 347-362, 2011.

[27] Y. Wang, Z. Yu, L. Shen, Y. Ge, and J. Li, "Different dominant models and fairness concern of E-supply chain," Complexity, vol. 2018, Article ID 8616595, 13 pages, 2018.

[28] Q. Li, M. Shi, and Y. Huang, "A dynamic price game model in a low-carbon, closed-loop supply chain considering return rates and fairness concern behaviors," International Journal of Environmental Research and Public Health, vol. 16, no. 11, p. 1978, 2019. 
[29] L. Kong, Z. Liu, Y. Pan, J. Xie, and G. Yang, "Pricing and service decision of dual-channel operations in an $\mathrm{O} 2 \mathrm{O}$ closedloop supply chain," Industrial Management \& Data Systems, vol. 117, no. 8, pp. 1567-1588, 2017.

[30] A. A. Taleizadeh, F. Akhavizadegan, and J. Ansarifar, "Pricing and quality level decisions of substitutable products in online and traditional selling channels: game-theoretical approaches," International Transactions in Operational Research, vol. 26, no. 5, pp. 1718-1751, 2017.

[31] W. Feng and H. Chen, "Bricks and clicks: decisions in an $\mathrm{O}_{2} \mathrm{O}$ supply chain considering product returns," IEEE Access, vol. 7, pp. 180292-180304, 2019.

[32] K. Cao, Y. Xu, J. Cao, B. Xu, and J. Wang, "Whether a retailer should enter an e-commerce platform taking into account consumer returns," International Transactions in Operational Research, vol. 27, no. 6, pp. 2878-2898, 2020.

[33] Y. Wang, Z. Yu, and L. Shen, "Study on the decision-making and coordination of an e-commerce supply chain with manufacturer fairness concerns," International Journal of Production Research, vol. 57, no. 9, pp. 2788-2808, 2018.

[34] Q. Han and Y. Wang, "Decision and coordination in a lowcarbon E-supply chain considering the manufacturer's carbon emission reduction behavior," Sustainability, vol. 10, no. 5, p. 1686, 2018.

[35] B. Yan, Z. Chen, X. Wang, and Z. Jin, "Influence of logistic service level on multichannel decision of a two-echelon supply chain," International Journal of Production Research, vol. 58, no. 11, pp. 3304-3329, 2019.

[36] J. Zhang, H. Li, R. Yan, and C. Johnston, "Examining the signaling effect of E-tailers' return policies," Journal of Computer Information Systems, vol. 57, no. 3, pp. 191-200, 2016.

[37] L. Xu, Y. Li, K. Govindan, and X. Yue, "Return policy and supply chain coordination with network-externality effect," International Journal of Production Research, vol. 56, no. 10, pp. 3714-3732, 2018.

[38] C. Wang, J. Chen, L. Wang, and J. Luo, "Supply chain coordination with put option contracts and customer returns," Journal of the Operational Research Society, vol. 71, no. 6, pp. 1003-1019, 2019.

[39] A. Borenich, Y. Dickbauer, M. Reimann, and G. C. Souza, "Should a manufacturer sell refurbished returns on the secondary market to incentivize retailers to reduce consumer returns?" European Journal of Operational Research, vol. 282, no. 2, pp. 569-579, 2019.

[40] Y. Li, L. Xu, and D. Li, "Examining relationships between the return policy, product quality, and pricing strategy in online direct selling," International Journal of Production Economics, vol. 144, no. 2, pp. 451-460, 2013.

[41] A. Balakrishnan, S. Sundaresan, and B. Zhang, "Browse-andSwitch: retail-online competition under value uncertainty," Production and Operations Management, vol. 23, no. 7, pp. 1129-1145, 2013.

[42] R. Batarfi, M. Y. Jaber, and S. M. Aljazzar, "A profit maximization for a reverse logistics dual-channel supply chain with a return policy," Computers \& Industrial Engineering, vol. 106, pp. 58-82, 2017.

[43] G. Ji, S. Han, and K. H. Tan, "False failure returns: optimal pricing and return policies in a dual-channel supply chain," Journal of Systems Science and Systems Engineering, vol. 27, no. 3, pp. 292-321, 2018.

[44] A. A. Taleizadeh, S. R. Beydokhti, and L. E. C. Barrón, "Joint determination of the optimal selling price, refund policy and quality level for complementary products in online purchasing," European J. of Industrial Engineering, vol. 12, no. 3, p. 332, 2018.

[45] M. Radhi and G. Zhang, "Pricing policies for a dual-channel retailer with cross-channel returns," Computers \& Industrial Engineering, vol. 119, pp. 63-75, 2018.

[46] Y. He, Q. Xu, and P. Wu, "Omnichannel retail operations with refurbished consumer returns," International Journal of Production Research, vol. 58, no. 1, pp. 271-290, 2019.

[47] L. Fan, T. L. Friesz, T. Yao, and X. Chen, "Strategic pricing and production planning using a Stackelberg differential game with unknown demand parameters," IEEE Transactions on Engineering Management, vol. 60, no. 3, pp. 581-591, 2013.

[48] S. Kolay and G. Shaffer, "Contract design with a dominant retailer and a competitive fringe," Management Science, vol. 59, no. 9, pp. 2111-2116, 2013.

[49] Z. Luo, X. Chen, J. Chen, and X. Wang, "Optimal pricing policies for differentiated brands under different supply chain power structures," European Journal of Operational Research, vol. 259, no. 2, pp. 437-451, 2017.

[50] H. Huang, H. Ke, and L. Wang, "Equilibrium analysis of pricing competition and cooperation in supply chain with one common manufacturer and duopoly retailers," International Journal of Production Economics, vol. 178, pp. 12-21, 2016.

[51] W. Ma, R. Cheng, and H. Ke, "Impacts of power structure on supply chain with a store brand," Asia-Pacific Journal of Operational Research, vol. 35, no. 4, Article ID 1850020, 2018.

[52] J. Zhao, X. Hou, Y. Guo, and J. Wei, "Pricing policies for complementary products in a dual-channel supply chain," Applied Mathematical Modelling, vol. 49, pp. 437-451, 2017.

[53] H. Ke, H. Huang, and X. Gao, "Pricing decision problem in dual-channel supply chain based on experts' belief degrees," Soft Computing, vol. 22, no. 17, pp. 5683-5698, 2017.

[54] S.-H. Chun and S. Y. Park, Hybrid Marketing Channel Strategies of a Manufacturer in a Supply Chain: Game Theoretical and Numerical Approaches, Information Technology and Management, vol. 20, no. 4, pp. 187-202, 2019.

[55] X. Chen, X. Wang, and X. Jiang, "The impact of power structure on the retail service supply chain with an $\mathrm{O} 2 \mathrm{O}$ mixed channel," Journal of the Operational Research Society, vol. 67, no. 2, pp. 294-301, 2016.

[56] S. Basak, P. Basu, B. Avittathur, and S. Sikdar, "A game theoretic analysis of multichannel retail in the context of "showrooming"” Decision Support Systems, vol. 103, pp. 34-45, 2017.

[57] J. Liu and H. Ke, "Firms' pricing strategies under different decision sequences in dual-format online retailing," Soft Computing, vol. 24, no. 10, pp. 7811-7826, 2019.

[58] L. Xu, Y. Li, K. Govindan, and X. Xu, "Consumer returns policies with endogenous deadline and supply chain coordination," European Journal of Operational Research, vol. 242, no. 1, pp. 88-99, 2015.

[59] J. Heydari and M. Ghasemi, "A revenue sharing contract for reverse supply chain coordination under stochastic quality of returned products and uncertain remanufacturing capacity," Journal of Cleaner Production, vol. 197, pp. 607-615, 2018.

[60] R. Yan and Z. Pei, "Return policies and $\mathrm{O}_{2} \mathrm{O}$ coordination in the e-tailing age," Journal of Retailing and Consumer Services, vol. 50, pp. 314-321, 2018.

[61] B. Gu, Y. Fu, and Y. Li, "Fresh-keeping effort and channel performance in a fresh product supply chain with loss-averse consumers' returns," Mathematical Problems in Engineering, vol. 2018, Article ID 4717094, 20 pages, 2018.

[62] X. Liu, Q. Gou, L. Alwan, and L. Liang, "Option contracts: a solution for overloading problems in the delivery service 
supply chain," Journal of the Operational Research Society, vol. 67 , no. 2, pp. 187-197, 2016.

[63] Z. Song and S. He, "Contract coordination of new fresh produce three-layer supply chain," Industrial Management \& Data Systems, vol. 119, no. 1, pp. 148-169, 2018.

[64] N. Amrouche, Z. Pei, and R. Yan, "Mobile channel and channel coordination under different supply chain contexts," Industrial Marketing Management, vol. 84, pp. 165-182, 2019.

[65] J. Dong, Z. Hu, and C. Liang, "E-commerce supply chain coordination under demand influenced by historical sales rate," in Proceeedings of the 2017 3rd International Conference on Information Management (ICIM), Chengdu, China, April 2017.

[66] M. Zhang, Y. Fu, Z. Zhao, S. Pratap, and G. Q. Huang, "Game theoretic analysis of horizontal carrier coordination with revenue sharing in E-commerce logistics," International Journal of Production Research, vol. 57, no. 5, pp. 1524-1551, 2018.

[67] Y. Zhong, F. Guo, Z. Wang, and H. Tang, "Coordination analysis of revenue sharing in E-commerce logistics service supply chain with cooperative distribution," SAGE Open, vol. 9, no. 3, 2019.

[68] Y. Wang, R. Fan, L. Shen, and W. Miller, "Recycling decisions of low-carbon E-commerce closed-loop supply chain under government subsidy mechanism and altruistic preference," Journal of Cleaner Production, vol. 259, p. 120883, 2020b.

[69] Y. Akcay, T. Boyac, and D. Zhang, "Selling with money-back guarantees: the impact on prices, quantities, and retail profitability," Production and Operations Management, vol. 22, no. 4, pp. 777-791, 2013.

[70] J. Chen and R. Grewal, "Competing in a supply chain via fullrefund and no-refund customer returns policies," International Journal of Production Economics, vol. 146, no. 1, pp. 246-258, 2013.

[71] Y. Xia, T. Xiao, and G. P. Zhang, "The impact of product returns and retailer's service investment on manufacturer's channel strategies," Decision Sciences, vol. 48, no. 5, pp. 918-955, 2016.

[72] B. Shen, R. Qian, and T.-M. Choi, "Selling luxury fashion online with social influences considerations: demand changes and supply chain coordination," International Journal of Production Economics, vol. 185, pp. 89-99, 2017.

[73] Q. Li, X. Chen, and Y. Huang, "The stability and complexity analysis of a low-carbon supply chain considering fairness concern behavior and sales service," International Journal of Environmental Research and Public Health, vol. 16, no. 15, p. 2711, 2019.

[74] J. Xie, L. Liang, L. Liu, and P. Ieromonachou, "Coordination contracts of dual-channel with cooperation advertising in closed-loop supply chains," International Journal of Production Economics, vol. 183, pp. 528-538, 2017.

[75] Q. Li, T. Xiao, and Y. Qiu, "Price and carbon emission reduction decisions and revenue-sharing contract considering fairness concerns," Journal of Cleaner Production, vol. 190, pp. 303-314, 2018.

[76] M. Reimann, "Accurate response with refurbished consumer returns," Decision Sciences, vol. 47, no. 1, pp. 31-59, 2015.

[77] S.-Y. Chang and T.-Y. Yeh, "A two-echelon supply chain of a returnable product with fuzzy demand," Applied Mathematical Modelling, vol. 37, no. 6, pp. 4305-4315, 2013.

[78] S. Scheriau, "Philips-consumer returned products," Master's thesis, University of Graz, Graz, Austria, 2016.

[79] Y. Wang, R. Fan, L. Shen, and M. Jin, "Decisions and coordination of green e-commerce supply chain considering green manufacturer's fairness concerns," International Journal of Production Research, pp. 1-19, 2020a.

[80] P.-L. To, C. Liao, and T.-H. Lin, "Shopping motivations on Internet: a study based on utilitarian and hedonic value," Technovation, vol. 27, no. 12, pp. 774-787, 2007.

[81] F. Kawaf and S. Tagg, "The construction of online shopping experience: a repertory grid approach," Computers in Human Behavior, vol. 72, pp. 222-232, 2017.

[82] J. Wang and X. Huang, "The optimal carbon reduction and return strategies under carbon tax policy," Sustainability, vol. 10, no. 7, p. 2471, 2018.

[83] R. Zhang, J. Li, Z. Huang, and B. Liu, "Return strategies and online product customization in a dual-channel supply chain," Sustainability, vol. 11, no. 12, p. 3482, 2019.

[84] L. Shen and Y. Wang, "Supervision mechanism for pollution behavior of Chinese enterprises based on haze governance," Journal of Cleaner Production, vol. 197, pp. 571-582, 2018. 